\title{
المشاتل في مدينة الكوت (دراسة في جغرافية الزراعة)
}

\section{م.د شاكر مسير لفته الزاملي}

جامعة واسط/ كلية التربية

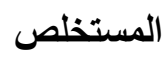

تعد المشاتل من أهم أسباب نجاح وتقدم النهضة الزراعية، اذ تعتمد على تطبيق الأساليب العلمية

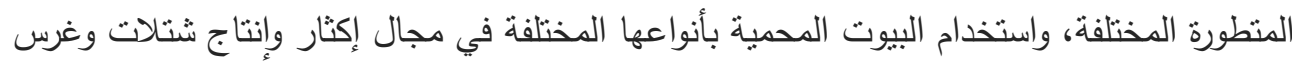

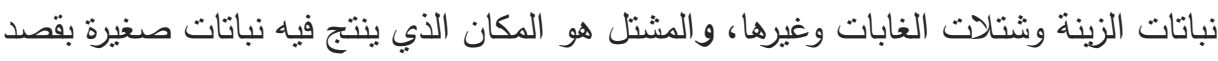

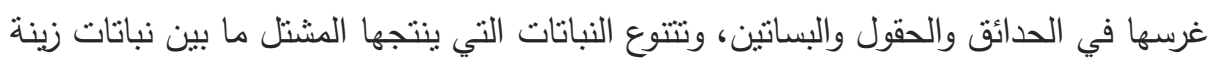

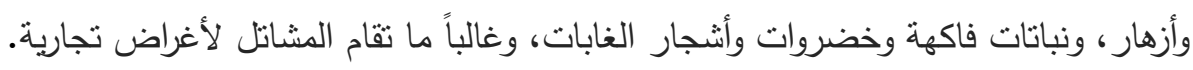

وتتأثر بمجموعة من العوامل الطبيعية من اهمها (المناخ والتربة) والعوامل البشرية من اهمها

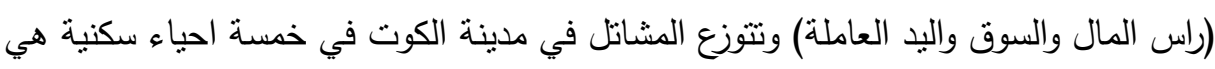
(الجعفرية والثرقية والكفاءات وحي الربيع وام اهليل ) وتعود ملكية هذه المشاتل منها للحكومة التهنة

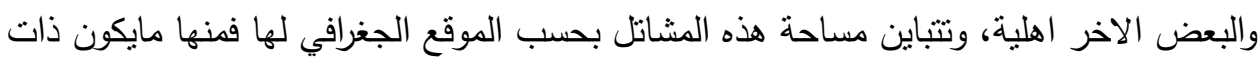

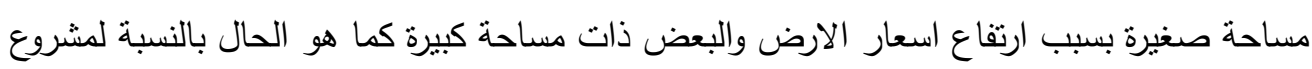

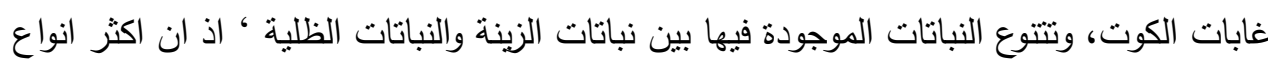
الثتلات الني يزداد الطلب عليها هي الورود. 


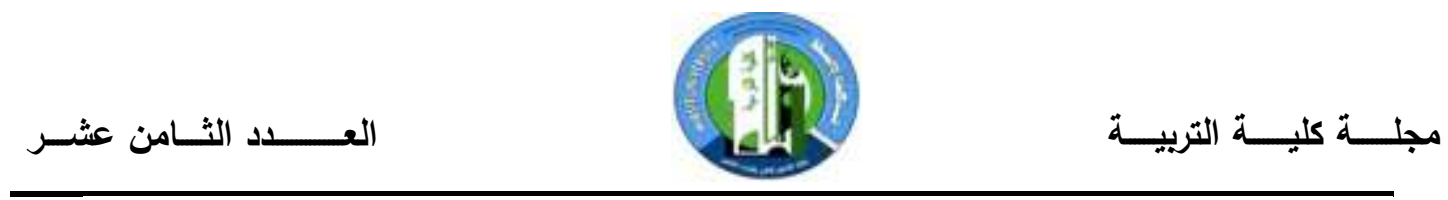

Nurseries in the city of Kut (the study of geography in agriculture )

\section{Dr.SHAKIR MASEER LAFTA AL-ZAMILI}

important reasons for the success and progress of agricultural renaissance , as it depends on the application of various advanced scientific methods , and the use of greenhouses of different kinds in the field of propagation and production of seedlings and planting of ornamental plants and seedlings of forest and other, and the nursery is a place where small plants produce intent to be planted in gardens and fields and orchards and varied plants that produced Arboretum between ornamental plants and flowers, plants and fruit and vegetables, trees and forests, often held nurseries for commercial purposes.

And influenced by a range of natural factors of the most important climate and soil ) and human factors of the most important ( capital market and labor ) and distributed nurseries in the city of Kut in five revive the housing is ( Jaafari, Eastern and competencies inspired spring WAM Ahallil) and is owned nurseries, including the government and others civil and vary space these nurseries, according to the geographical location have the mismatch Maicon with a small area because of high land prices and other large space, as is the case for the project Kut forests , and varied in the plants of ornamental plants and plants silhouettes ' as the most common type of seedlings, which increases the demand for them is roses .

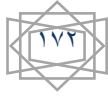




\section{المقدمة}

ان عملية اقتتاء المشاتل ظاهرة حضارية اخذت بالزيادة في السنوات الاخيرة نتيجة لتحسين

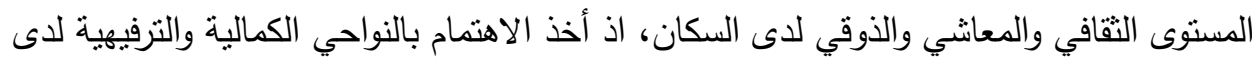

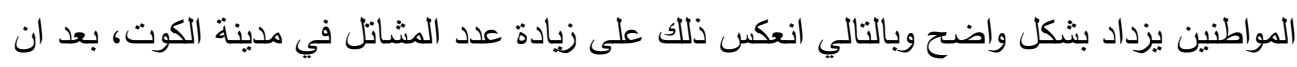

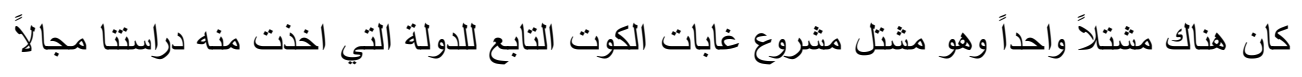

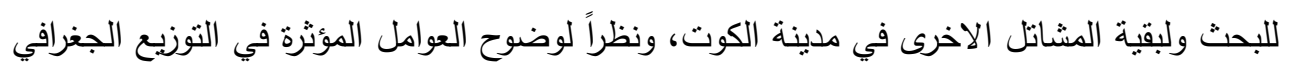

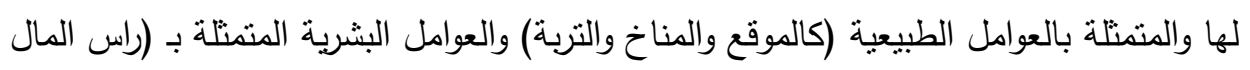
والخبرة الفنية (الايدي العاملة) والسوق وطرق النقل).

وان اثر العوامل الطبيعية في النوزيع الجغرافي للمشاتل يبدو ضئيلاً، وذلك لاهتمام المزارعين خلال

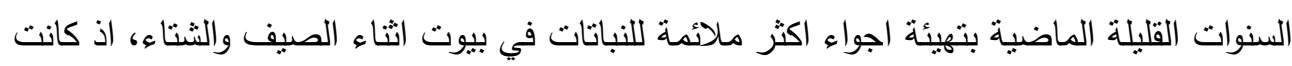

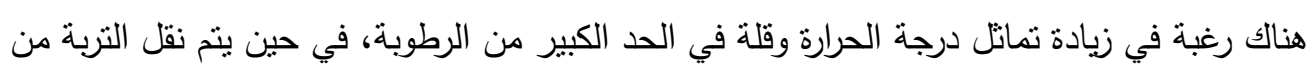

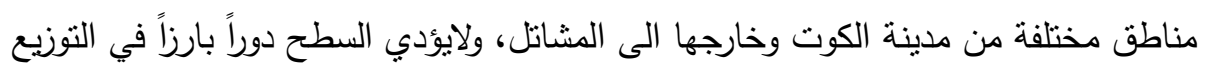

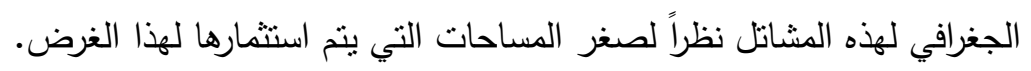

ومن هنا جاء البحث بعدة محاور هي:اولاً : مفهوم المشاتل وأنواعها واهميتها وأهدافها وفوائدها وجماليتها البيئية وشروط انشاءها.

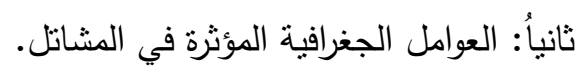

ثالثاً: التحليل المكاني للمشاتل في مدينة الكوت وتوزيعها الجغرافي.

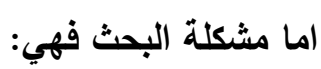

1- ما هي الخصائص الجغرافية للمشاتل في مدينة الكوت. r- ما مقومات انشاء المشاتل في مدينة الكوت. r- كيف تتوزع المشاتل جغرافياً في مدينة الكوت.

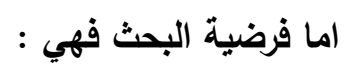


1- ان للششاتل دوراً كبيراً في الاهمية الجمالية في مدينة الكوت من حيث شكلها وانواعها وتغيراتها

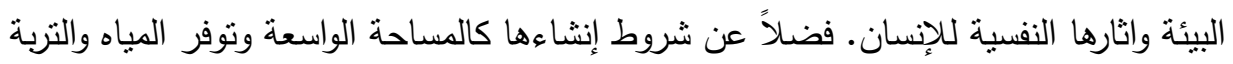
الجيدة ومخازن جيدة لحفظ البذور والأسمدة والساندين وبيوت زجاجية او بلاستيكية وغيرها.

r- يرتبط عدد المشاتل وأنواعها في مدينة الكوت بالظروف الطبيعية والعوامل البشرية.

r- تتنتر معظم مشاتل مدينة الكوت في المنطقة المركزية.

وتأتي اهية البحث من حيث ابراز دور المشاتل في الجمالية البيئية في مدينة الكوت وتأثيراتها في التغيرات البيئية رغم المساحة الصغيرة التني نتغلها.

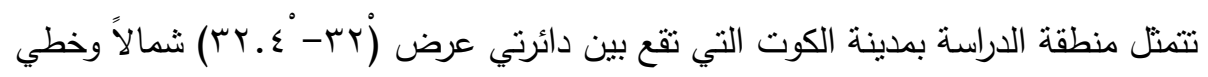

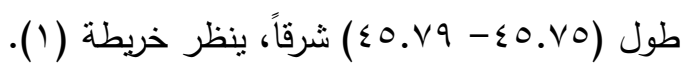

\section{المحور الاول: مفهوم المشاتل وأهميتها.}

اولاً: مفهوم المشتل: يعني المشتل قطعة من الارض تختص لإكثار وتربية النباتات والعناية بها

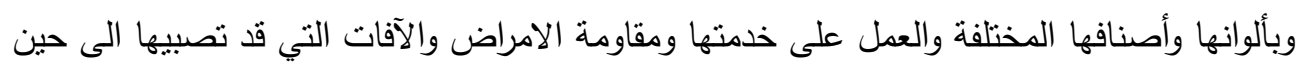

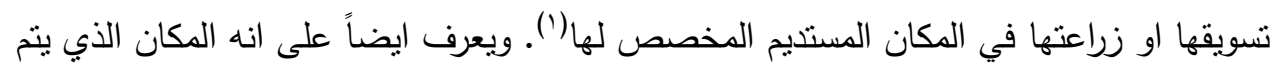
فيه جميع العطليات اللازمة للحصول على البادرات لاستخدامها في عملية التتجير (؟).

$$
\text { وتقسم المشاتل من حيث الملكية الى (r): }
$$

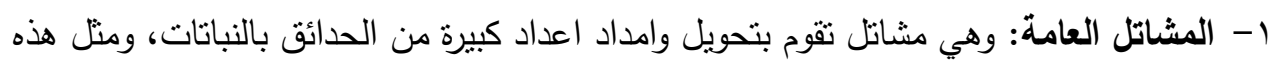

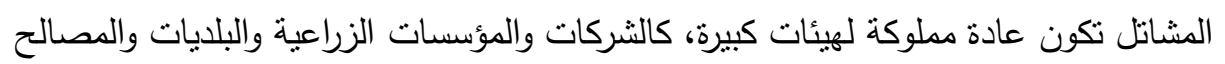

الحكومية كمصلحة البساتين والمعاهد والكليات الزراعية .

r- المشاتل التجاريةة: وهي مشاتل تقوم لأغراض تجارية، ويملكها الافراد لإنتاج نباتات الزينة والاتجار

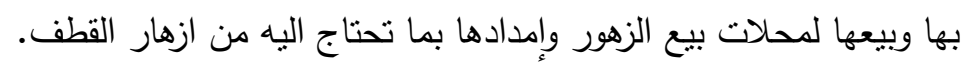

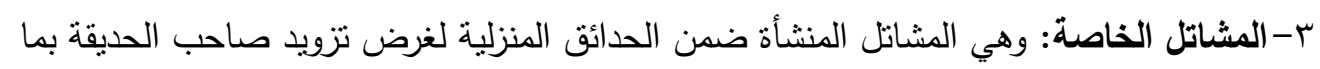

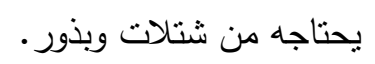

اما انواع المشاتل من حيث التخصص وبند والمحاصيل الزراعية التي تتنجها تقسم الى اربعة انواع: 1- مشتل الفاكهة: هو مشتل متخصص لإنتاج وإكتار شتلات الفاكهة. 


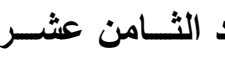

)

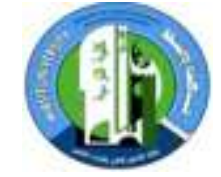

مجلـــة كليــــة التربيـــة

r- مشتل الخضر : هو مشتل متخصص لانتاج واكثار شتلات الخضر.

r- مشتل الزينة : هو مشتل متخصص لانتاج واكثار نباتات الزينة والزهور المختلطة .

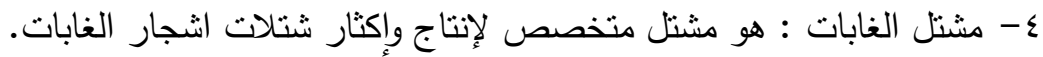

خريطة ( r r م) موقع محافظة واسط من العراق والتصميم الاساس لمدينة الكوت

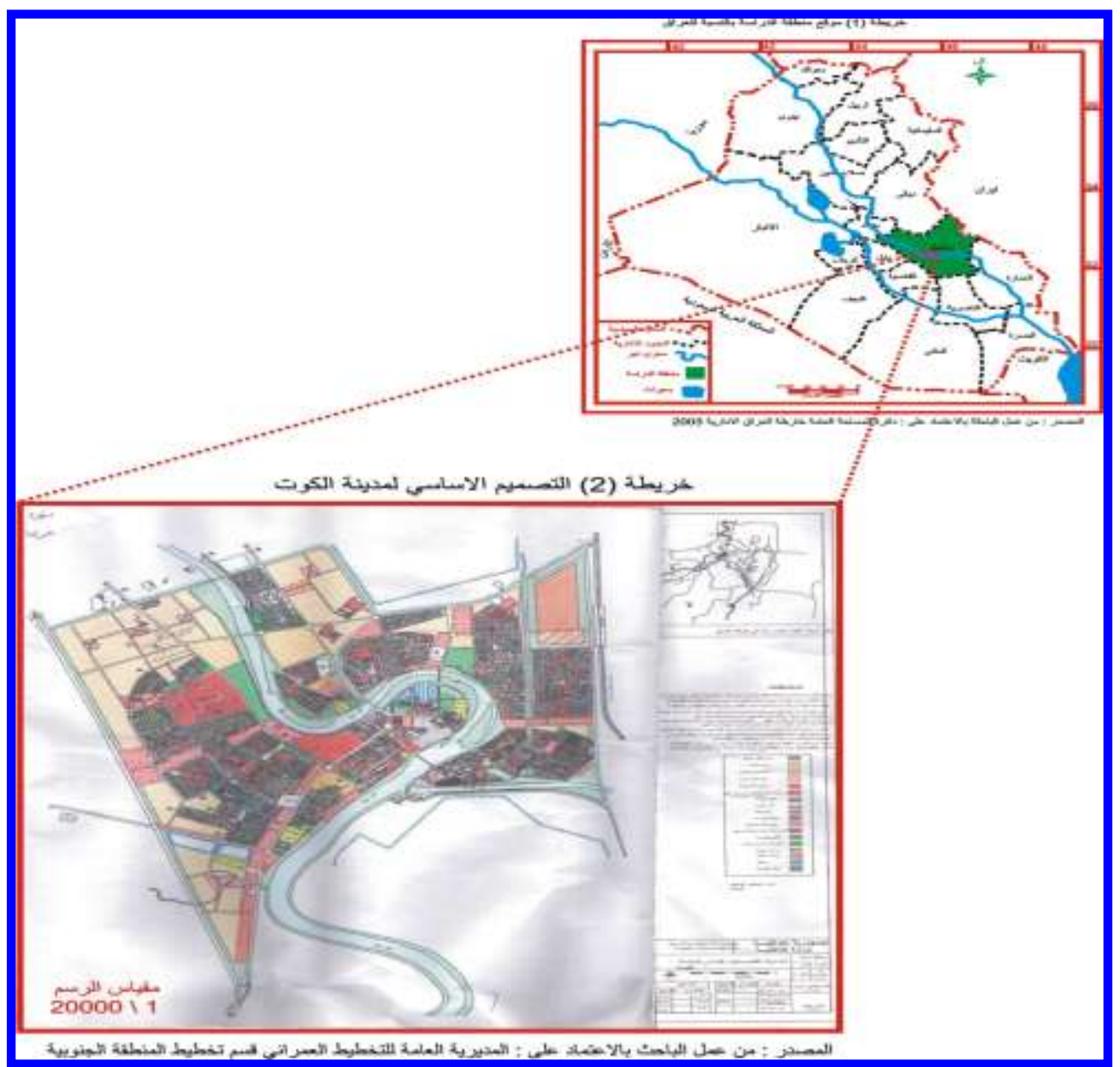


اهمية المشتل واهد(فه وفوائده

1ـ اهمبة المشتل

غالبا ما تقدم المشاتل لاغراض تجارية ، من اجل ذلك فان الانشطة التي تقوم بها تمند لتصل الى دلى

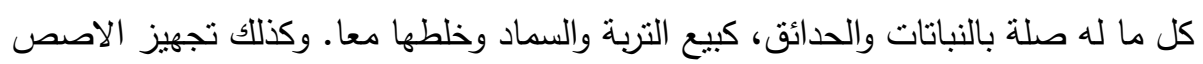

والحاويات التي توضع بها النباتات وتوفير مختلف انواع من المعدات البستتة واثاث الحدائق (').

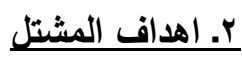

ان الهدف الرئيس لإنشاء المشتل في الامانات والبلديات هو المحافظة على الصفات الوراثية للانواع

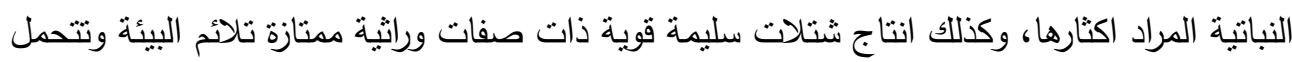

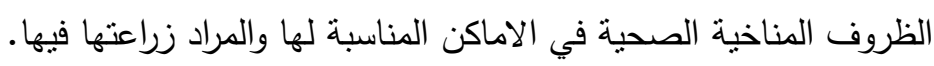

كما يفضل زراعة ارض المشتل ببعض المحاصيل البقولية لاستعمالها كاسمدة خضراء لزيادة خصوبتها ولزيادة المادة العضوية فيها (r).

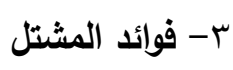

تعد المشاتل من اهم اسباب نجاح وتقدم النهضة الزراعية، اذ تعتمد على تطبيق الاساليب الغلمية

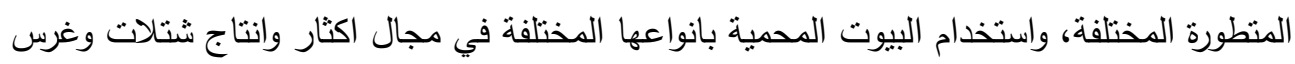
نباتات الزينة وشتلات الغابات وغيرها، ويمكن تحديد الاهداف من اقامة المشاتل في ما يلي : 1- نوفير الظروف البيئية لإكثار الثتلات بالبذور او الاجزاء الخضرية، وكذلك لتوسيع الثتلات اللازمة للزراعة داخل المدن. ץ- انتاج الثتلات الجيدة من الاصناف الممتازة، وشتلات النباتات الكبيرة.

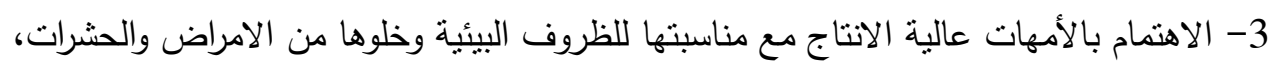

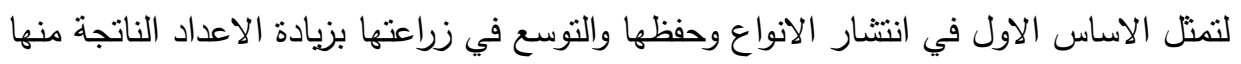
بالإكثار الخضري. 
ع - تشغيل الايدي العاملة وزيادة الخبرة والتنريب.

0- امداد الحدائق بالثتلات والنباتات اللازمة للزراعة في اوقات محددة، وكذللك لتعويض النقص

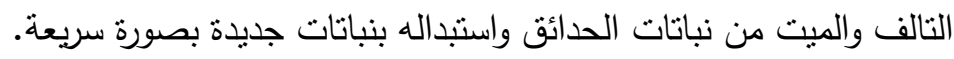

6- توفير الظروف البيئية المتحكم بها وخاصة لاجراء التجارب والابحاث الزراعية للوقوف على الوسائل المتلى في زراعة ورعاية وخدمة المشاتل لزيادة الانتاج وتحسين نوعية المحاصيل البستانية.

7 - ازدياد السعى لملئ الفراغات داخل المنازل وخارجها بنباتات او شجيرات او حتى اشجار تضيف

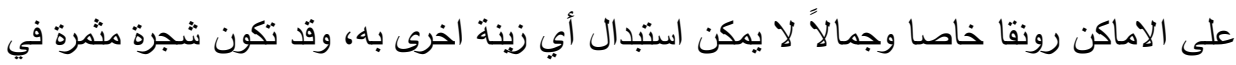

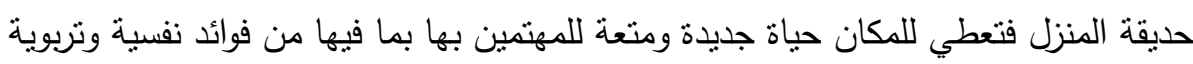

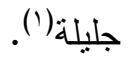

ثالثاً:- شروط انشاء المشتل:

يجب ان يتوقف في الموقع الذي سيقام عليه المشتل مايلي:

1. وجود مصدر جيد للمياه مثل ترعة او توفير المياه الجوفية لضمان وجود مصدر مستمر لري الثتلات حتى لا تجف او تموت.

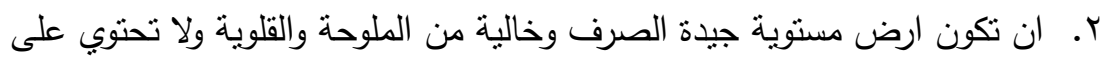

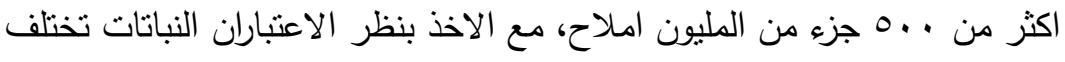

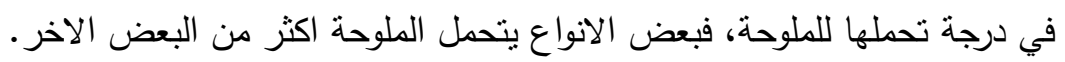

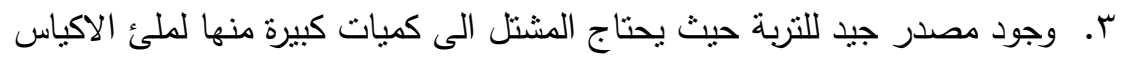
المستخدمة في تقريد النباتات.

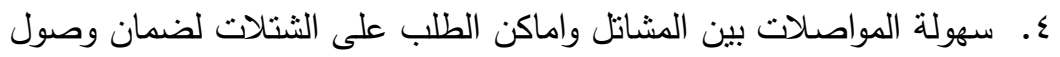
الثتلات الى اماكن زراعتها المستديمة بحالة جيدة. 0. توفير العمالة حيث يحتاج المشتل الى عمالة كثيفة خاصة في فترة تفريد البادرات لملئ الاكياس وزراعة البادرات. 7. ضرورة زراعة مصدات من الاشجار او الثجيرات الثوكية لحماية الثتلات والنباتات من الرياح، وتوفير الحماية للمشتل. 
V . . مكان مستوف لثروط تخزين الاسمدة الكيمياوية(؟). ^. مكان مسنوف لنروط تخزين الاسمدة العضوية والتزبة والسنادين. 9. مخازن لحفظ البذور والادوات والمبيدات.

• 1. اماكن مظللة لتجفيف البذور وتجهيز خلطات التربة اللازمة للسنادين وتتمية النباتات بعد اخراجها من البيوت الزجاجية او البلاسنيكية.

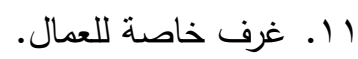
r ا. مبنى لإدارة اعمال الشتل وحفظ السجلات. r ا ـ بيوت زجاجية او بلاستيكية وظلل خثبية ومراقد باردة وحارة.

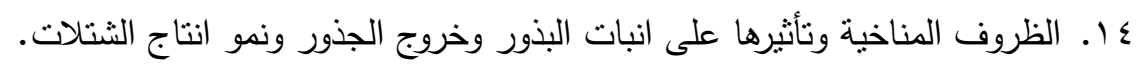

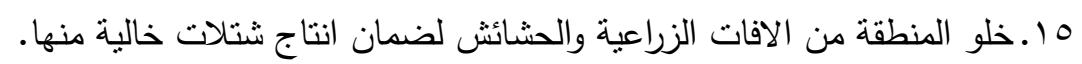

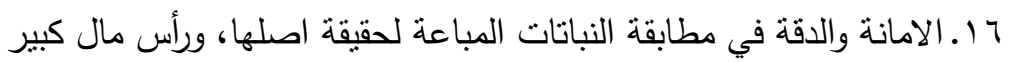

$$
\text { لكلابتداء) (r) }
$$

\section{رابعاً:-- استخذام الدورة الزراعية في المشتل:}

ينصح دائما بأن يكون هناك دورة زراعية في المشتل وخاصة في ذلك الجزء المخصص لإنتاج

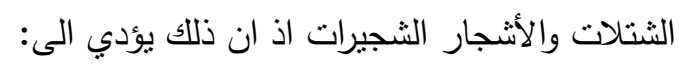

1- توفير الثتلات الجيدة سنويا بحجم مناسب وعمر مناسب في الاوقات الملائمة لنقلها وحسب

$$
\text { احتياجات السوق. }
$$

r- عدم اجهاد التربة والمحافظة على منسوبها من الانخفاض اذ يتم تبادل زراعة شتلات النباتات

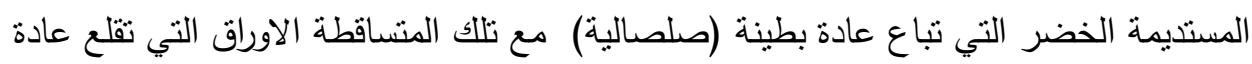

$$
\text { ملثا (يعني بدون تربة حول الجذور) . }
$$

r- تخصيص قطعة ارض لكل عمر من الشتلات المختلفة ولكل نوع وصنف حتى تسهل عمليات الخدمة وتوفير الاحتياجات المناسبة للنباتات.

ع - اتباع الدورة المناسبة يقلل من مرض انتثار الافات ويسهل اجراء المقاومة المناسبة عند حدوث

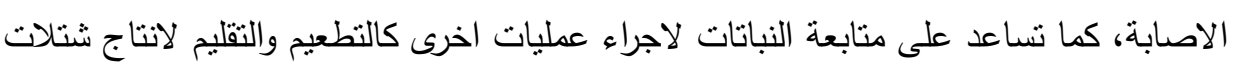


يجب ان تقسم الارض الى اجزاء بينها ممرات واسعة تكفي لنقل الادوات ونقل الثتلات، ويقسم

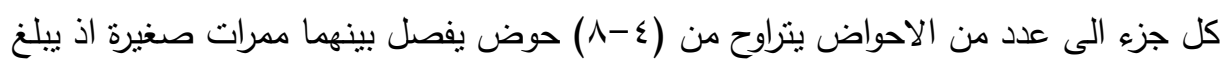

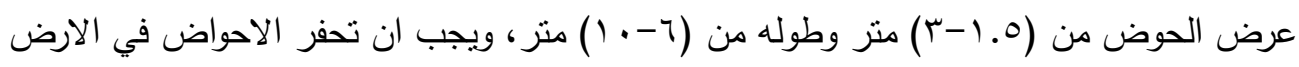

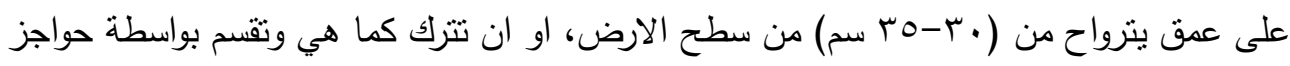

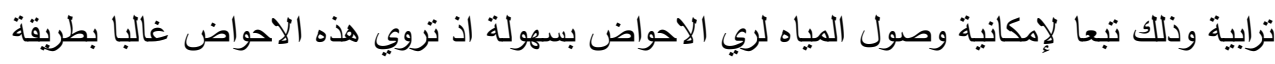

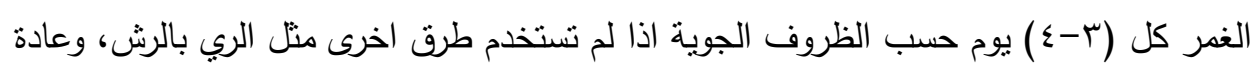

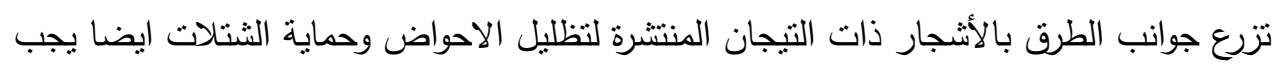

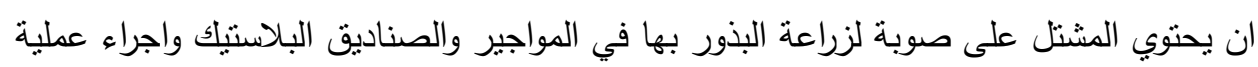
التقريد بها حتى نجاحها ثم تتقل الى الخارج. وفي المشاتل الصغيرة يمكن الاكتفاء بصوبة من جذوع الاثجار تغطي من اعلى للتظليل وفي

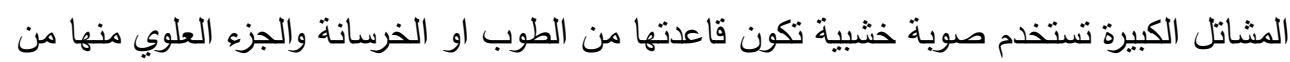

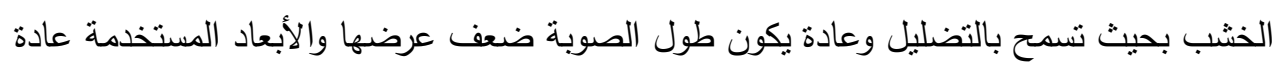

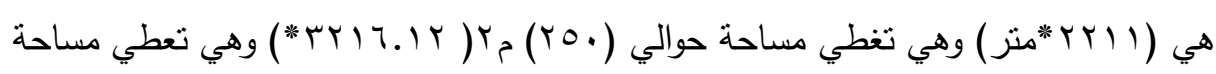

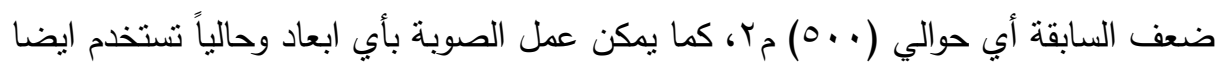

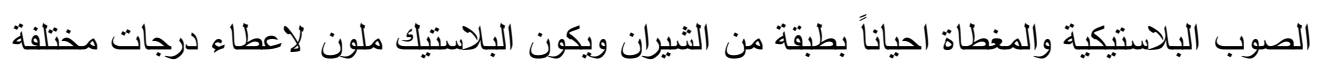

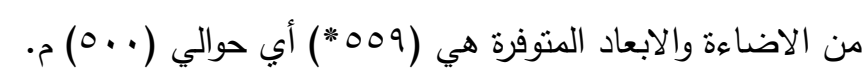

فضلا عن ما سبق يجب ان يحتوي المشتل على مكان كاف لخلط التربة وملئ الاكياس (مربع

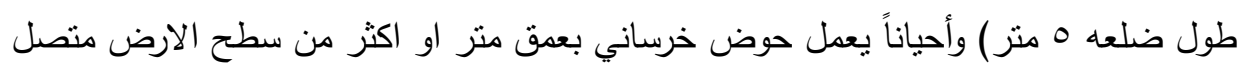

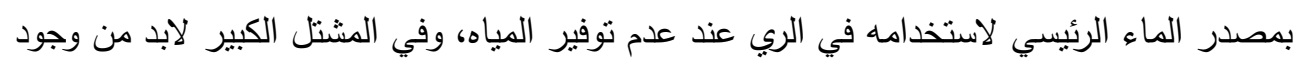

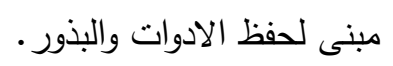

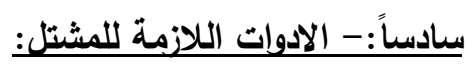
يلزم تواجد بعض الادوات لتسهيل العمليات الزراعية المختلفة بالمشتل وهذه الادوات هي: ا - الفأس البلدي والفرنساوي: بيتخدم لتجهيز وتمزيق التربة.

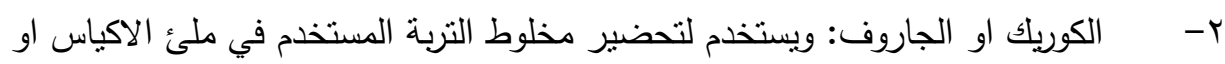
الاصص. - المص

$$
\text { ب- الكرك: بستخدم بجمع الاوراق الجافة وتسوية سطح الارض. }
$$

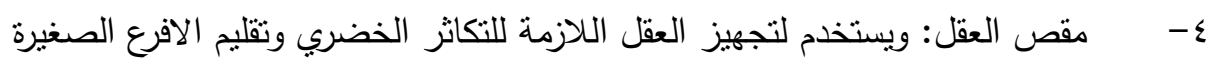


0- - - المنشار او السراق: ويستخدم في ازالة الافرع الخشبية الكبيرة.

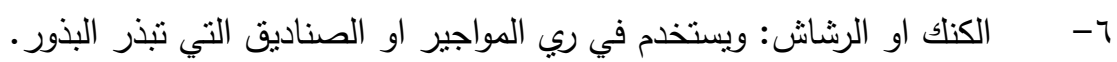

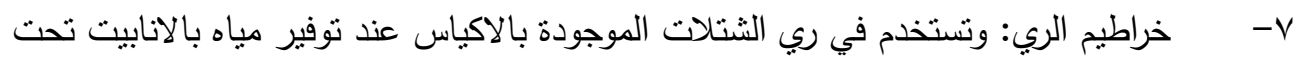

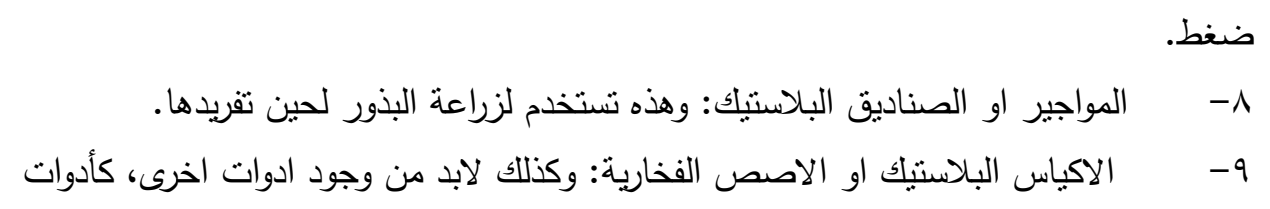

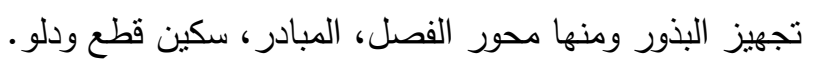

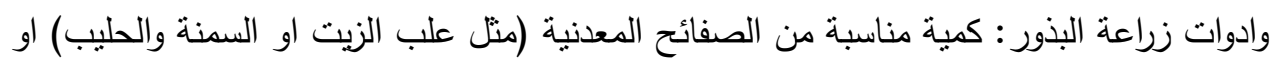
الاحواض البلاستيكية الخاصة للزراعة.

ادوات فصل الفسائل: خطاف، عنلة (عوجة) ومطرقة.

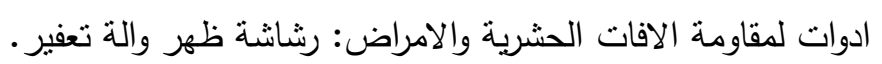

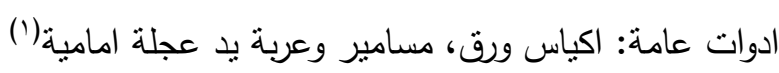

\section{المحور الثاني : العوامل الجغرافية الموئثرة في انشاء المشاتل في مدبنة الكوت}

\section{أولاً: العوامل الطبيعة:}

إن للعوامل الطبيعية تأثيراً على المشاتل اذ لا بد من نوفر المقومات الطبيعية من مناخ وتربة

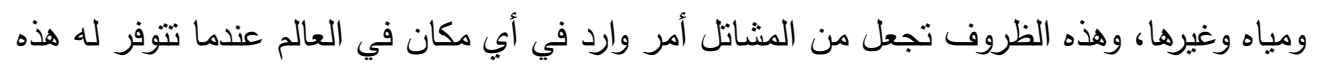
المقومات لإنجاح زراعة الثنتلات.

يمتاز مناخ مدينة الكوت بالتتوع الفصلي فيتضح فيه فصلان رئيسان هما الصيف والثتاء واما

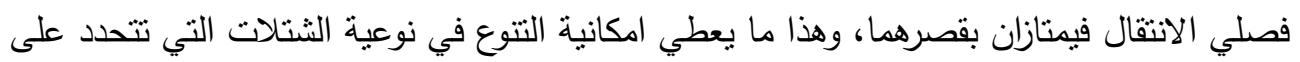
اساس التغير الفصلي في مناخ الددينة.

وتمتاز ايضاً بسطح منبسط وذا تربة خصبة تكونت من رواسب نهر دجلة التي تعد جزء من رواسب السهل الرسوبي.

ومن أهم العوامل الطبيعية: 
1- المناخ: يعد المناخ من أهم العوامل التي لها ثأثيراً كبيراً على تصميم المشتل، لأنه معرّض بشكل

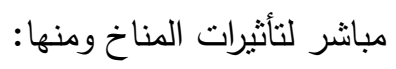

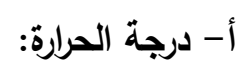

وتعد من العوامل المؤثرة على عناصر ومحتويات الششتل وبالتالي على تصميم المشتل، فهي

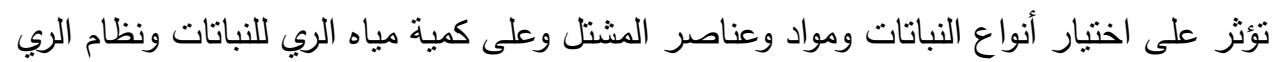

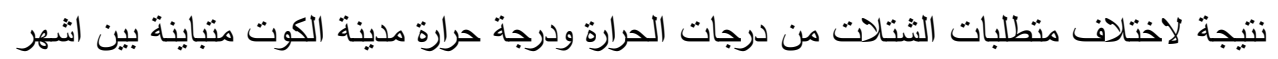

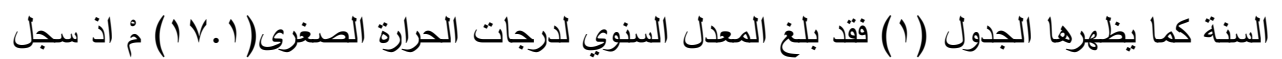

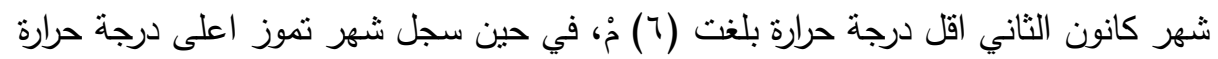

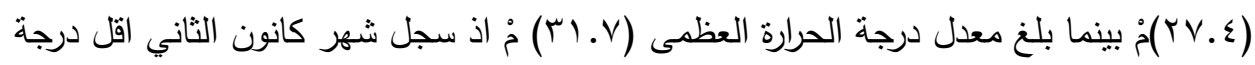

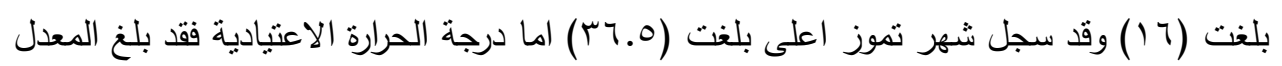

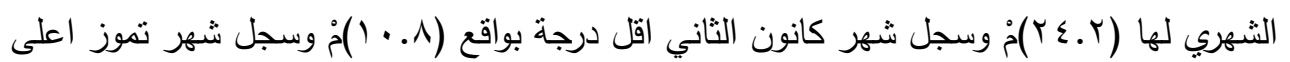

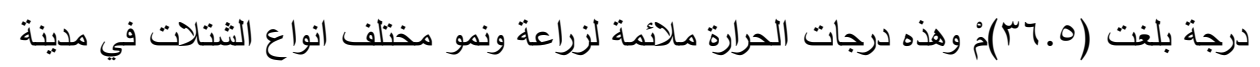
الكوت.

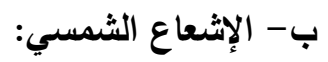

هنالك شتلات تتحمل شدة الإشعاع الثمسي ونتباين هذه من حيث كثافتها وارتفاعها ونوعيتها

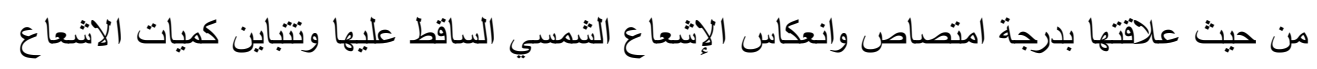

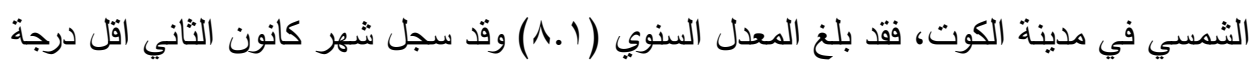

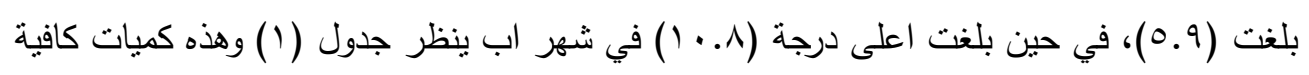

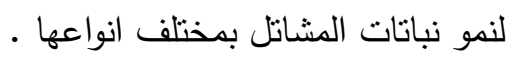

ج- الرياح: للرياح اثر مهم في تصميم المشتل، من حيث اختيار الموقع للمشتل وكذلك من حيث

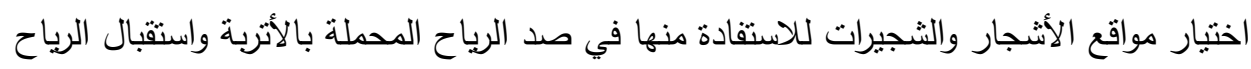

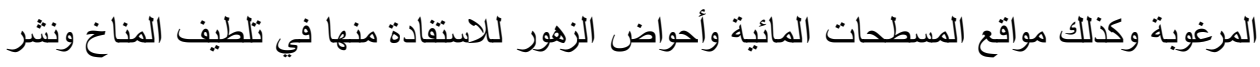

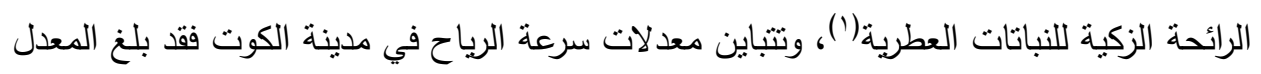




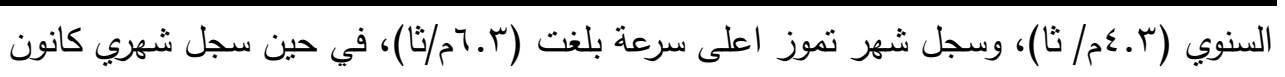

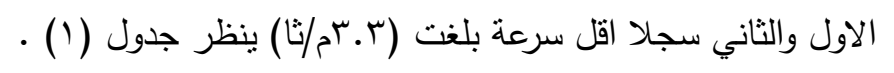

د - الرطوية: وتؤثر مع معدل سقوط الأمطار على تصميم المشتل من حيث:

- اختبار أنواع النباتات (أثنجار ، شجيرات، مسطحات خضراء).

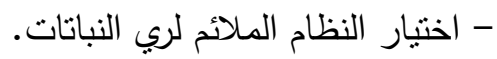
- اختيار نظام تصريف مياه الأمطار . - اختيار تتسيق النباتات.

وتتباين درجات الرطوبة في مدينة الكوت فقد بلغ المعدل السنوي للرطوبة النسبية (9.9 ؛ )، وقد

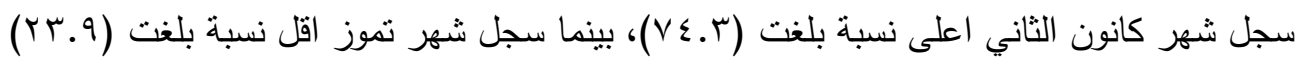
ينظر جدول (1). (1) - (1) - (1)

جدول (1) المعدلات الثهرية والسنوية لعناصر المناخ في محطة الكوت للمدة ( ؟9 99 1 ${ }^{(*)}(r \cdot 1 r$ 
العــــــدد الثـــامن عدب

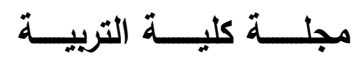

المصدر : وزارة النقل والمواصلات ، الهيئة العامة للانواء الجوية والرصد الزلزالي ، قسم المناخ ،

\begin{tabular}{|c|c|c|c|c|c|c|}
\hline 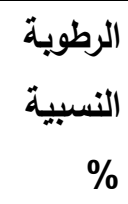 & الرياح & الاشعاع & درجة الحرارة & درجة الحرارة & الصغزرى مُ الحراة & العند \\
\hline 74.3 & 3.3 & 5.9 & $1 . .1$ & 17 & 7 & كانون الثاني \\
\hline 64.9 & 3.6 & 6.4 & $1 Y .9$ & 19.1 & $V .0$ & شباط \\
\hline 57.3 & 4 & 7.8 & IV.z & ד.Tr & 11.7 & اذار \\
\hline 47.7 & 4 & 6.8 & $r \leq$ & r. & 18.1. & نيسان \\
\hline 32.7 & 4.2 & 8 & o. & rᄉ.r & rr & مايس \\
\hline 24.9 & 5.7 & 9.7 & $r \varepsilon . V$ & $\varepsilon r . q$ & ro & حزيران \\
\hline 23.9 & 6.3 & 10.1 & r.o & $\varepsilon 0 . r$ & YV.E & تموز \\
\hline 25.9 & 5.9 & 10.8 & م. & $\leqslant 0.1$ & rч.1 & اب \\
\hline 29.4 & 4.7 & 9.8 & T.V & $r \leq .7$ & YY.S & ايلول \\
\hline 40.2 & 3.6 & 7.6 & ro.9 & ro.r & $11 . \varepsilon$ & تشرين الاول \\
\hline 57.6 & 3.5 & 6.8 & 11.1 & $19 . r$ & Ir.r & تشربن الثاني \\
\hline 72.1 & 3.3 & 6.8 & 14.9 & 18.1 & A.r & كانون الاول \\
\hline 45.9 & 4.3 & 8.1 & $r \leqslant . r$ & T.V & $1 V .1$ & المعدل \\
\hline
\end{tabular}

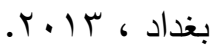


من أهم العوامل البيئية الطبيعية التي لها تأثير كبير على تصميم المشتل، اذ أن عملية اختيار

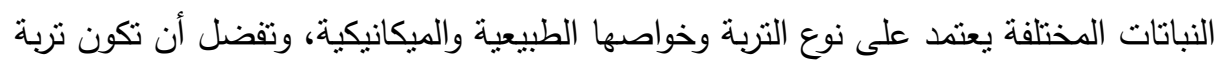

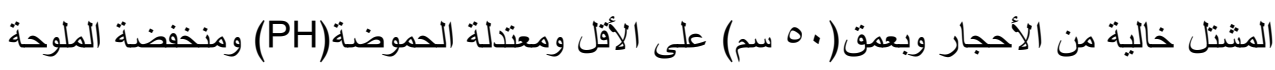

\section{ثُانباً: العوامل البشرية:}

يرتبط التوزيع الجغرافي للمشاتل ارتباطاً وثيقاً بالعوامل البشرية، ومنها:

I ـ رأس المال: هو أحد العناصر الرئيسية المهمة التي يجب أخذها بعين الاعتبار ، ويلزم للابتداء

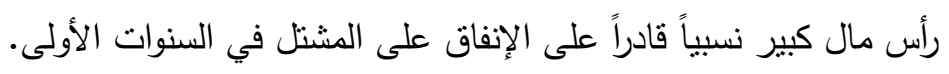

r • توفر الخبرة الفنية(الأيدي العاملة): من أهم الأمور التي يجب أن تؤخذ بنظر الاعتبار هو

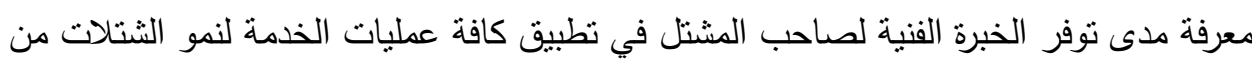

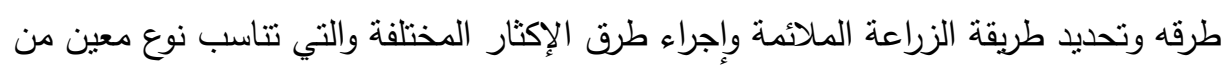

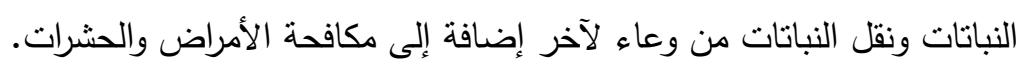

r • السوق: يعد السوق من العوامل الأساسية التي يجب مراعاتها قبل إنثاء أب مشروع اقتصادي لغرض تصريف منتجاته.

والمشاتل من المشاريع التي تتطلب أسواقاً واسعة لغرض تصريف منتجاته لذا لا يمكن تجاهل

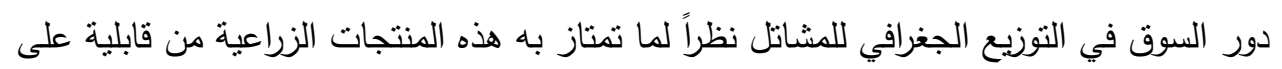

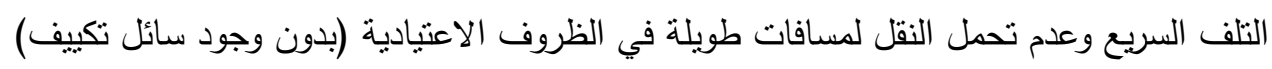

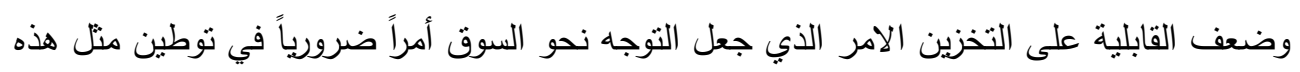

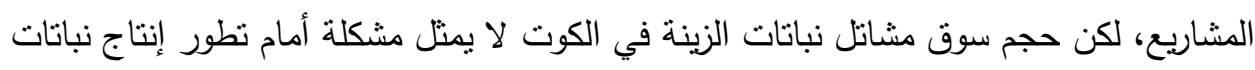

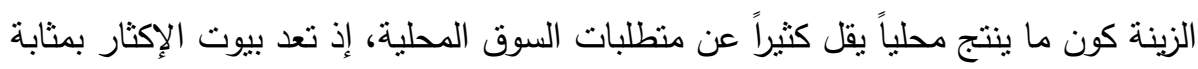

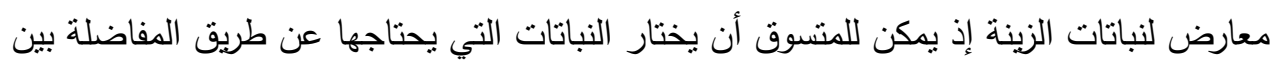

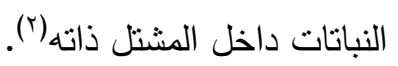


؛ · طرق النقل:

لطرق النفل اثرة مهم في اختيار المشتل لما توفره من سهولة الوصول للمشتل فضلاً عن نقل المواد الأولية الضرورية للمشتل وسهولة تسويق منتجاته إلى أسواق استهلاكها(؟).

وتقل مبيعات المشاتل التي تقع على شوارع فرعية عن تللك التي تقع على شوارع رئيسة، إذ

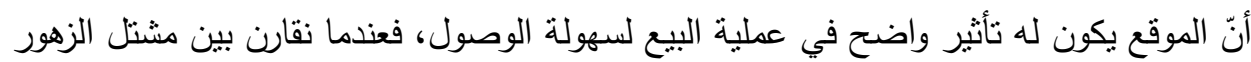

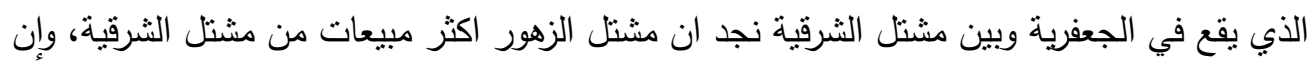
وجود مكان مخصص لوقوف السيارات يساعد على إمكانية نقل النباتات والأصص(الأوعية) والتربة التئية ويوفر إمكانية حركة العمال.

ه . مساحة الأرض(المكان) يعد المكان من ضروريات انشاء المشتل لاسيما اذا ماتوفرت مساحة مناسبة وذات موقع جغرافي مهم مع الاخذ بنظر الاعتبار سعر الارض سواء كانت ملك او ايجار.

\section{المحور الثالث : التحليل المكاني للمشاتل في مدينة الكوت وتوزيعها الجغرافي:}

يقتصر تواجد المشاتل في مدينة الكوت على خمس مناطق وهي( الجعفرية، الشرقية، الكفاءات،

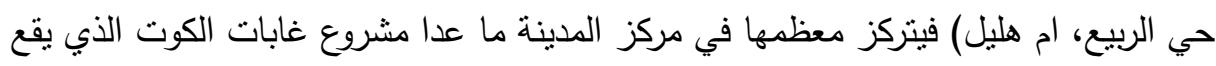

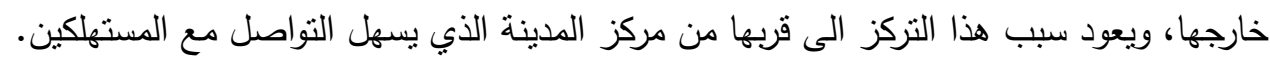

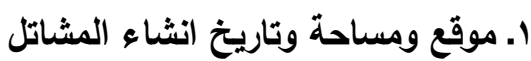

تتوقف مساحة المشتل على عدد الثتلات المراد إنتاجها سنوياً وعلى موقع المشتل فكلما اقترب

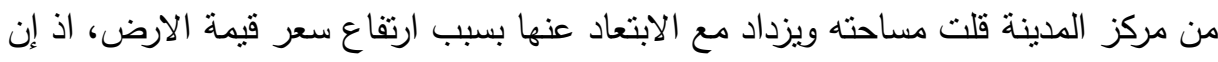

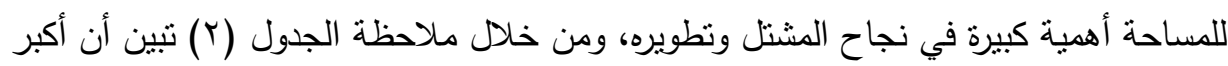

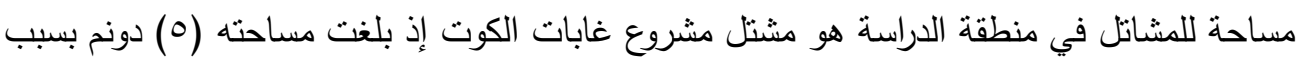

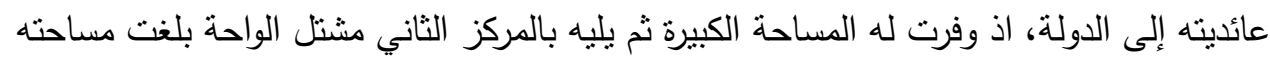

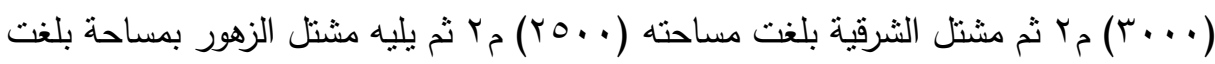

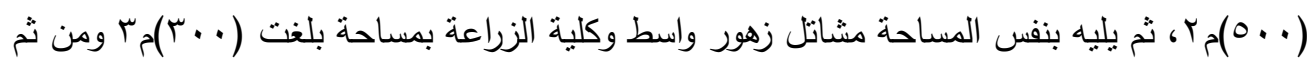

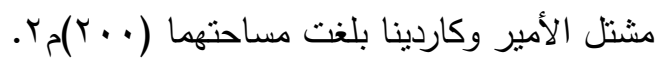




\begin{tabular}{|c|c|c|c|c|}
\hline المساحة مج & تاريخ الإنشاء & الموقع & اسم المشتل & $ت$ \\
\hline $0 .$. & $r \cdot 11$ & الجعفرية & الزهور & 1 \\
\hline$r \ldots$ & $r \ldots r$ & الجعفرية & الامير & $r$ \\
\hline ro.. & 191. & الثرقية & الشرقية & $r$ \\
\hline r... & $r \ldots v$ & الكفاءات & الواحة & $\varepsilon$ \\
\hline$r \ldots$ & $r \ldots \varepsilon$ & الجعفرية & زهور واسط & 0 \\
\hline r.. & $r \cdot 11$ & الحاوي & كلية الزراعة & 7 \\
\hline r... Y Y Y & r.IT & الجعفرية & كاردينا & $\mathrm{v}$ \\
\hline 1Yo.. & 1970 & ام هليل & مشروع غابات الكوت & $\wedge$ \\
\hline
\end{tabular}

المصدر : من عمل الباحث بالاعتماد على الدراسة الميدانية.

\section{ץ- ملكية المشتل}

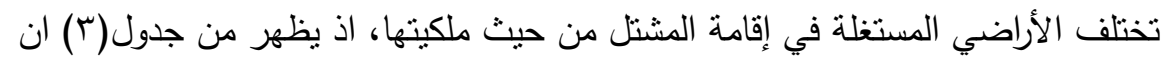

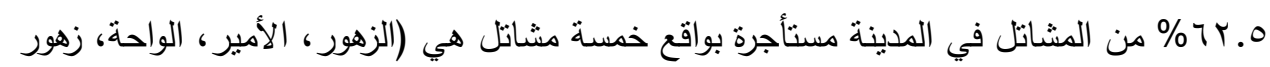

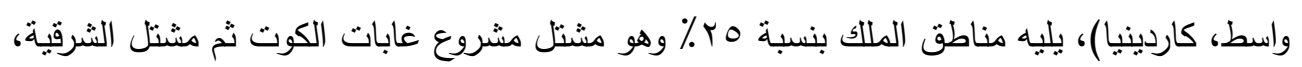

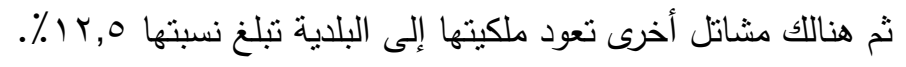




\begin{tabular}{|c|c|c|c|}
\hline 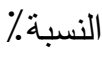 & 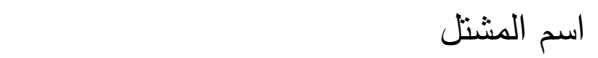 & 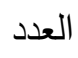 & ملكية الارض \\
\hline ro & مشتل كلية الزراعة، مشروع غابات الكوت & r & ملك \\
\hline$T r, 0$ & الزهور ، الأمير ، الواحة، زهور واسط، كاردينيا & 0 & ايجار \\
\hline $1 Y, 0$ & 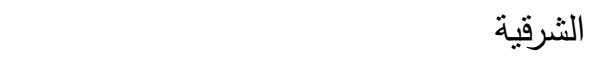 & 1 & أخرى \\
\hline $1 \cdots$ & & $\wedge$ & 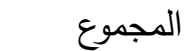 \\
\hline
\end{tabular}

المصدر : من عمل الباحث بالاعتماد على الدراسة الميدانية.

\section{ب-عوامل اختيار موقع المشتل}

تتباين أسباب اختيار المشتل حسب موقعه وهذا يرجع إلى مجموعة من الأسباب كان القرب من

السوق اهمها اذ نشكل نسبة 0.

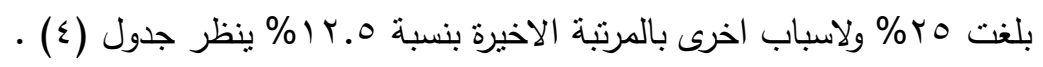

\begin{tabular}{|c|c|c|c|}
\hline & \multicolumn{3}{|c|}{ جدول (ع) عوامل اختيار موقع المشتل في مدينة الكوت } \\
\hline النسبة\%٪ & 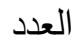 & سبب اختيار مكان المشتل & $ت$ \\
\hline ro & r & 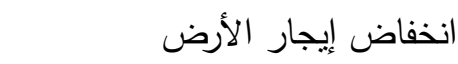 & 1 \\
\hline ro & r & قربه من طرق النقل & r \\
\hline- & - & احتواء مساكن المنطقة على حدائق & r \\
\hline$r v, 0$ & r & قربه من السوق لسكان المنطقة & $\varepsilon$ \\
\hline $1, T, 0$ & 1 & أخرى & 0 \\
\hline $1 \cdots$ & $\wedge$ & 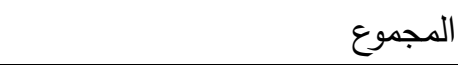 & \\
\hline
\end{tabular}

المصدر : من عمل الباحث بالاعتماد على الدراسة الميدانية. 
يعد راس المال أحد أهم العناصر الضرورية لإنشاء المشاتل، لإيجار الأرض أو شراءها وشراء

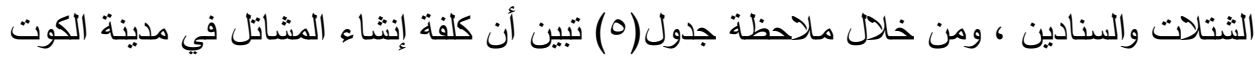

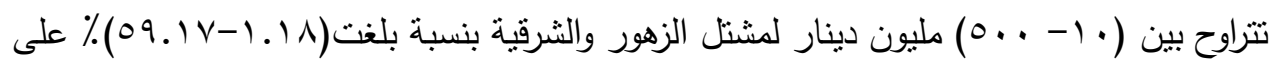

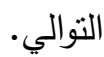

جدول (0) كلفة انشاء المشاتل في مدينة الكوت

\begin{tabular}{|c|c|c|c|}
\hline$\%$ & كلفة الإنشاء (دينار ) & اسم المشتل & ت \\
\hline$\leq, 1 \leq$ & 0ب مليون & كلية الزراعة & 1 \\
\hline 1,70 & ع ا مليون & الأمير & r \\
\hline 1,11 & • 1 مليون & الزهور & $r$ \\
\hline $11, \wedge r$ & . . . مليون & الواحة & $\varepsilon$ \\
\hline $1 \wedge, 94$ & . 1 مليون & مشروع غابات الكوت & 0 \\
\hline i,r. & 11 11 & كاردينيا & 7 \\
\hline $1, V V$ & 10 مليون & زهور واسط & v \\
\hline $09,1 \mathrm{~V}$ & . . . مليون & الثرقية & $\wedge$ \\
\hline $1 \ldots$ & & المجموع & \\
\hline
\end{tabular}

المصدر : من عمل الباحث بالاعتماد على الدراسة الميدانية. 


\section{ه-عدد العاملين في المشتل}

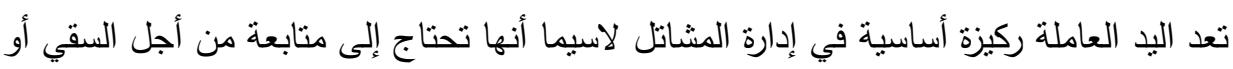
إضافة الأسمدة أو حتى زرع الثتلات والعناية المستمرة، وبذلك يتحدد عدد العاملين بحسب مساحة

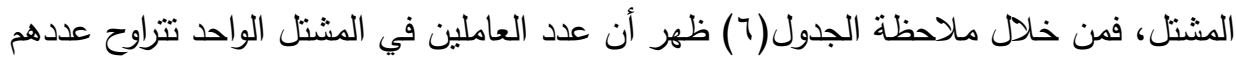

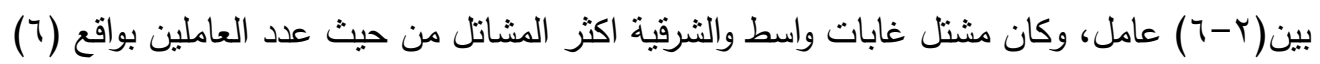
عاملاً، واقلها في مشتل الامير وكاردينيا بواقع عاملين لكل منهما.

جدول (؟) عدد العاملين في مشاتل مدينة الكوت

\begin{tabular}{|c|c|c|c|}
\hline$\%$ & عدد العاملين & اسم المشتل & ت \\
\hline 17,77 & 0 & كلية الزراعة & 1 \\
\hline$r$. & 7 & مشروع غابات الكوت & r \\
\hline r. & 7 & الثرقبة & r \\
\hline 1. & $r$ & الزهور & $\varepsilon$ \\
\hline 1. & r & الواحة & 0 \\
\hline 7,77 & $r$ & الامير & 7 \\
\hline 1. & r & زهور واسط & V \\
\hline 7,77 & r & كاردبنبا & $\wedge$ \\
\hline 11 & r. & & المجمو المو \\
\hline
\end{tabular}

المصدر : من عمل الباحث بالاعتماد على الدراسة الميدانية لسنة با ـ ؟. 
4-مصدر تزويد المشتل بالمياه

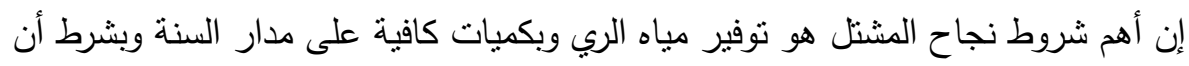
تكون المياه قليلة الأملاح وغير عسرة اذ يؤدي استخدام المياه العسرة إلى رفع تركيز أيون الهيدروجين في التربة، ويفضل استعمال مياه الأنهار أو مياه الثرب للاري، وفي حالة استعمال الري الرذاذئي الرياه

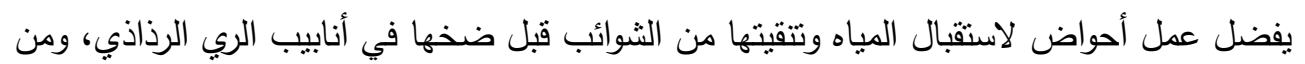

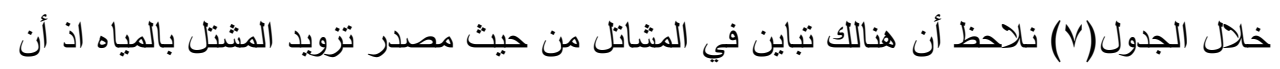

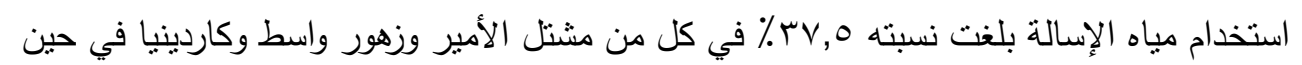

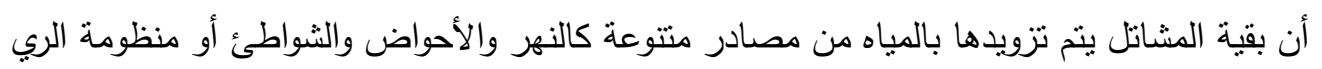
الرذاذية أو مياه الخام أو مياه صحية.

جدول (V) مصدر تزويد المشتل بالمياه في مدينة الكوت

\begin{tabular}{|c|c|c|c|c|}
\hline النسبة\% & 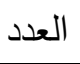 & اسم المشتل & مصدر تزويد المشتل بالمياه & $ت$ \\
\hline$r v, 0$ & r & الأمير ، زهور واسط، كاردينيا & مياه إسالة إلة & 1 \\
\hline Ir,o & 1 & كلية الزراعة & 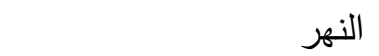 & r \\
\hline $1 Y, 0$ & 1 & الزهور & مياه صحية & r \\
\hline Ir,o & 1 & الثرقية & الخام & $\varepsilon$ \\
\hline Ir,o & 1 & الواحة & الأحواض والثواطئ & 。 \\
\hline Ir,o & 1 & مشروع غابات الكوت & منظومة الري والرذاذية & 7 \\
\hline $1 \ldots$ & $\Lambda$ & & المجموع & \\
\hline
\end{tabular}

المصدر : من عمل الباحث بالاعتماد على الدراسة الميدانية. 


\section{V - vوع التربة المستعملة في المشتل}

إن للتربة اثرا أساسيا في عملية الإنبات من حيث توفير المواد العضوية والمعدنية اللازمة للنباتات وكنلك يعتمد نمو النبات على عدد من الخصائص التي يجب أن تتوفر في التربة، من أهها

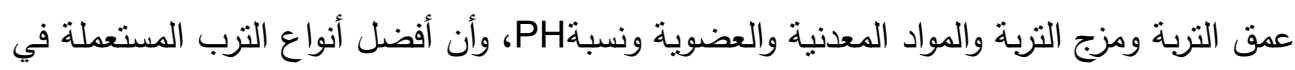

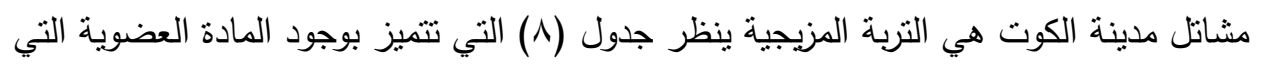

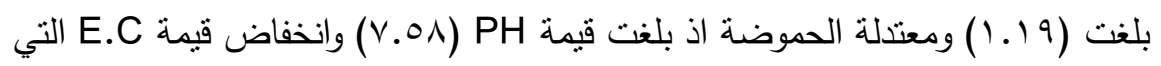

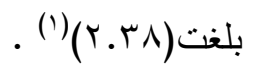

جدول (^) نوع التربة المستعملة في المشاتل في مدينة الكوت

\begin{tabular}{|c|c|c|c|}
\hline النسبة \% & اسم المشتل & العدد & نوع التربة \\
\hline $1 \ldots$ & الكوت، كاردينيا، زهور واسط، الأمير، الزهور، الواحة، مشروع غابات & $\wedge$ & التربة \\
\hline
\end{tabular}

المصدر : من عمل الباحث بالاعتماد على الدراسة الميدانية.

\section{1-طريقة زرع الثتلات في المشتل}

هنالك عدة طرق لزراعة الثتلات أهمها البذور وهي الخطوة التي تسبق عملية إنتاج الثتلات، اذ

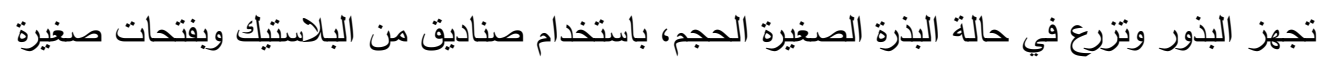

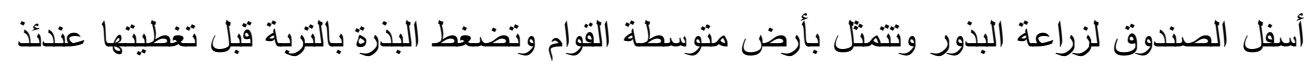

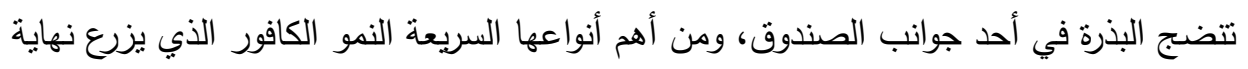

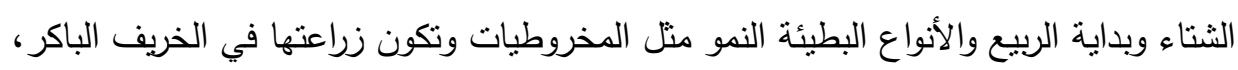

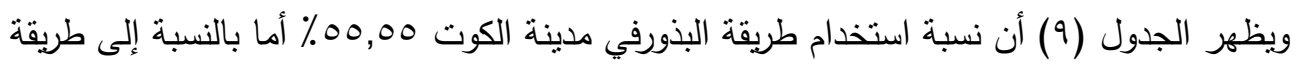

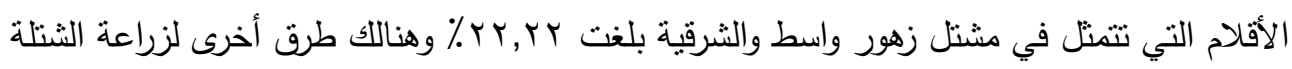

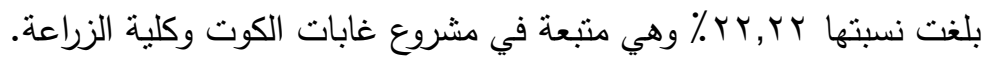




\begin{tabular}{|c|c|c|c|}
\hline \multicolumn{4}{|c|}{ جدول (9) طريقة زرع الثتلات في مشاتل مدينة الكوت } \\
\hline 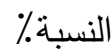 & 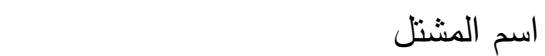 & 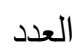 & طريقة زرع الشتلة \\
\hline 00,00 & الزهور ، الثرقية، كاردينيا، الأمير ، الواحة & ○ & 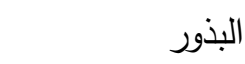 \\
\hline rr, r & زهور واسط، الشرقية & r & الأقلام \\
\hline Tr, r & مشروع غابات الكوت، كلية الزراعة & r & 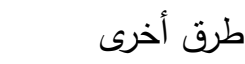 \\
\hline $1 \cdots$ & & 9 & 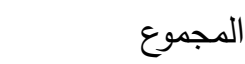 \\
\hline
\end{tabular}

المصدر : من عمل الباحث بالاعتماد على الدراسة الميدانية.

$$
\text { 9- الادوات المستعملة في المشتل }
$$

إن الأدوات والمعدات الزراعية والعمليات الفنية لها اثر أساسي في عملية الزراعة داخل الشثل

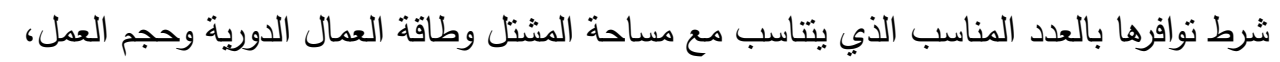
ومنها أدوات تجهيز البذور وأدوات الزراعة والري والتطعيم وغيرها، ومن خلال ملاحظة الجدول( • (1) )

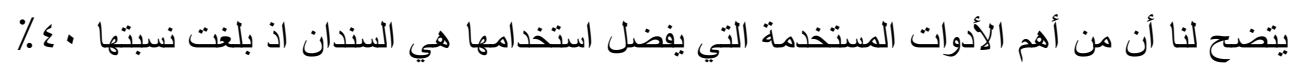

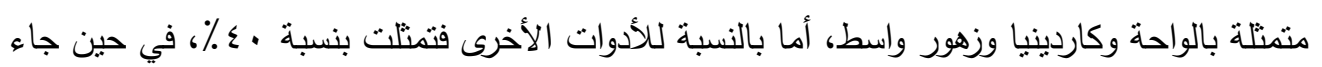

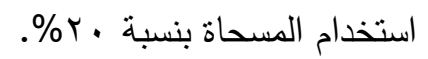


جدول ( • ( ) الأدوات المستعملة في مشاتل مدينة الكوت

\begin{tabular}{|c|c|c|c|}
\hline 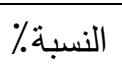 & اسم المشتل & العدد & 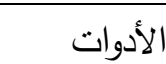 \\
\hline$r \cdot$ & الزهور ، كاردينيا & r & 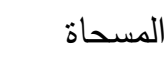 \\
\hline$\varepsilon$ & الواحة، كاردينيا، الأمير ، زهور واسط & $\varepsilon$ & 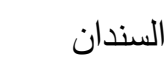 \\
\hline$\varepsilon$ & كاردينيا، كلية الزراعة، الشرقية، مشروع غابات الكوت & $\varepsilon$ & 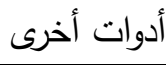 \\
\hline $1 \ldots$ & & 1. & المجموع \\
\hline
\end{tabular}

المصدر : من عمل الباحث بالاعتماد على الدراسة الميدانية.

\section{• 1-انواع الشتلات الموجودة في المشتل}

تتباين أنواع الثتلات في المشنل الواحد ومن أهمها نباتات الزينة التي نشمل مشتل الزهور والنباتات الظلية ونتشل مشتل كاردينيا والأمير وزهور واسط، ويجب أن تكون الثنتلات أصيلة خالية من العيوب جيدة التجذير خالية من الإصابة المرضية والحشرية وجيدة النمو والتقرع، وتتضمن النباتات المزروعة في مشاتل الفاكهة المستديمة والنفضية ونباتات خضر صيفية وشتوية وشجيرات ومنسلقات ومسطحات خضراء وغيرها، ويتضح من الجدول (1) (1) أن نباتات الزينة والنباتات الظلية تفوق الأنواع الأخرى من الثتلات حيث بلغت نسبتها . ٪\%، أما الأنواع الأخرى من الثتلات فبلغت

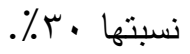

جدول (11) أنواع الثتنلات الموجودة في مشاتل مدينة الكوت

\begin{tabular}{|c|c|c|c|}
\hline 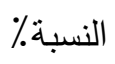 & 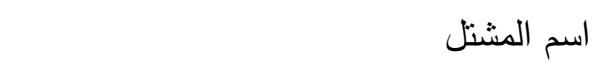 & 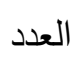 & أنواع الشتنلات \\
\hline$v$. & الزهور ، كاردينيا، الأمير ، الواحة، زهور واسط & $v$ & نباتات الزينة \\
\hline r. & كلية الزراعة، الشرقية، مشروع غابات الكوت & r & أنواع أخرى \\
\hline $1 \ldots$ & & 1. & 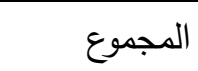 \\
\hline
\end{tabular}

المصدر : من عمل الباحث بالاعتماد على الدراسة الميدانية. 


\section{1 - أنواع الثتلات الأكثر استهلاكاً}

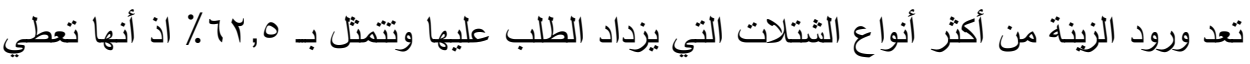

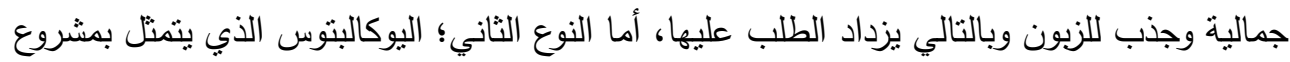

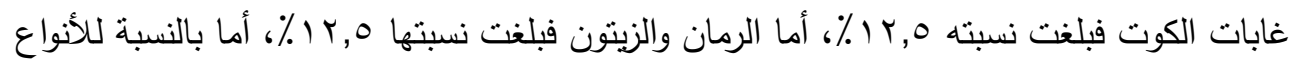

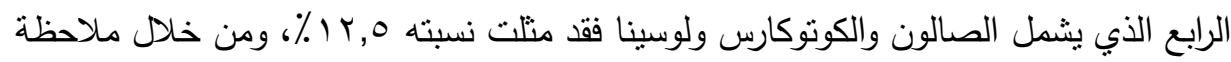

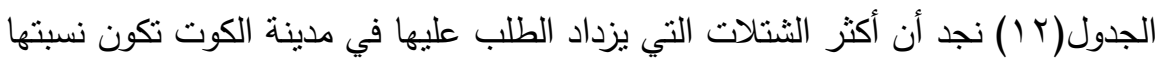

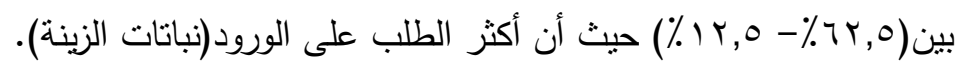
جدول (Y Y) أنواع الثتلات الأكثر استهلاكاً في مشاتل مدينة الكوت

\begin{tabular}{|c|c|c|c|}
\hline 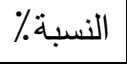 & اسم المشتل & 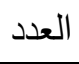 & 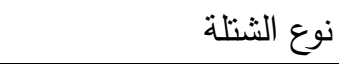 \\
\hline $1 r, 0$ & مشروع غابات الكوت & 1 & اليوكالبتوس \\
\hline$\pi r, 0$ & الامير ، الواحة، كاردينيا، زهور واسط،الزهور & ० & الورود (نباتات الزينة) \\
\hline $1 r, 0$ & كلية الزراعة & 1 & 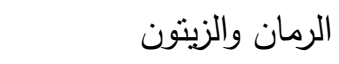 \\
\hline $1 r, 0$ & 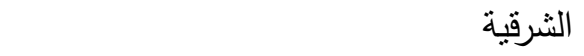 & 1 & صالون كوتوكارس لوسينا \\
\hline $1 \ldots$ & & $\wedge$ & المجموع \\
\hline
\end{tabular}

المصدر : من عمل الباحث بالاعتماد على الدراسة الميدانية. 
تصاب الشتلات بأنواع وبأعداد مختلفة من الأمراض والآفات التي تؤثر على نمو النباتات، ومن

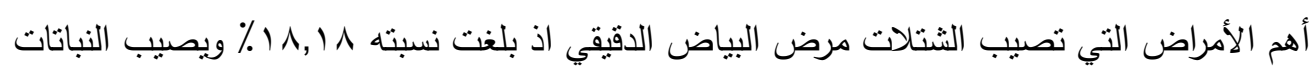

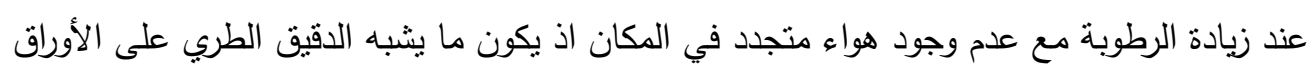

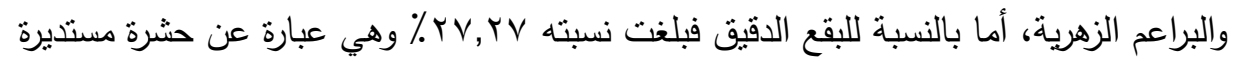

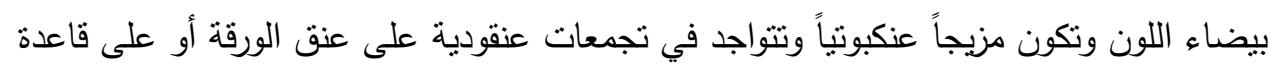

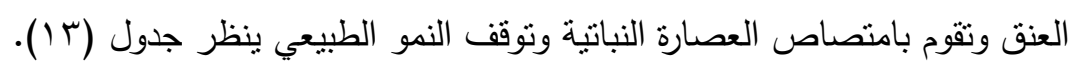

\begin{tabular}{|c|c|c|c|}
\hline \multicolumn{4}{|c|}{ جدول (با ) الأمراض الأكثر انتشاراً في الشتلات } \\
\hline 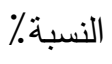 & 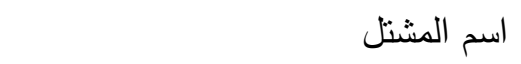 & 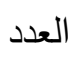 & 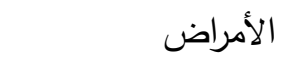 \\
\hline צח, דיץ & الثرقية، كلية الزراعة، كاردينيا، الواحة & $\varepsilon$ & الفطريات \\
\hline$r V, r V$ & زهور واسط، الأمير ، كاردينيا & r & البقع الدقيق \\
\hline $1 \wedge, 11$ & 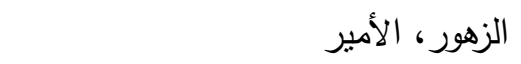 & r & البياض على الأوراق \\
\hline$\wedge ! 6) \wedge$ & كلية الزراعة، مشروع غابات الكوت & r & 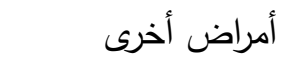 \\
\hline $1 \ldots$ & & 11 & 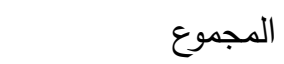 \\
\hline
\end{tabular}

المصدر : من عمل الباحث بالاعتماد على الدراسة الميدانية.

\section{rا - أفضل أنواع الأسمدة المستخدمة في المشتل}

تعد الأسمدة من العناصر الأساسية التي تحتاج إليها الثتلات لنساعدها في عملية الإنبات، ومن

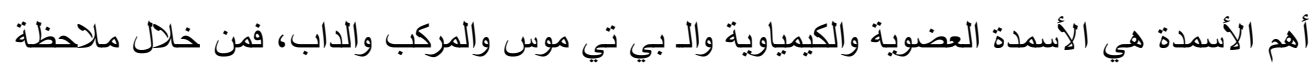

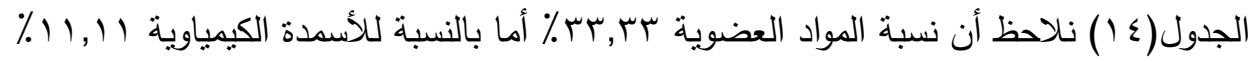
وكذلك بالنسبة للمركب والداب. 


\begin{tabular}{|c|c|c|c|}
\hline & \multicolumn{3}{|c|}{ جدول (ع ا) أفضل أنواع الأسمدة المستخدمة في مشاتل مدينة الكوت } \\
\hline النسبة \% & اسم المشتل & 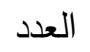 & أفضل أنواع الأسمدة \\
\hline سז, - & كاردينيا، كلية الزراعة، الأمير & r & الأسمدة العضوية \\
\hline 11,11 & الواحة & 1 & الأسددة الكيمياوية \\
\hline س & زهور واسط، الشرقية، الزهور & $r$ & بي تي موس \\
\hline 11,11 & مشروع غابات الكوت & 1 & المركب \\
\hline 11,11 & الواحة & 1 & 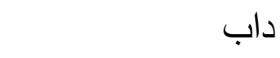 \\
\hline $1 \ldots$ & & 9 & المجموع \\
\hline
\end{tabular}

المصدر : من عمل الباحث بالاعتماد على الدراسة الميدانية. 
يبين الجدول (10) إن أهم الثتلات الصالحة للزراعة في مدينة الكوت هو اليوكاربس اذ تمنل

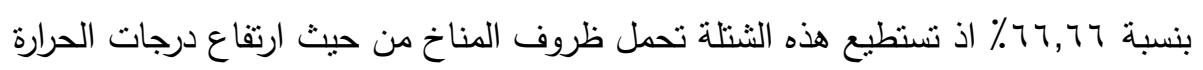

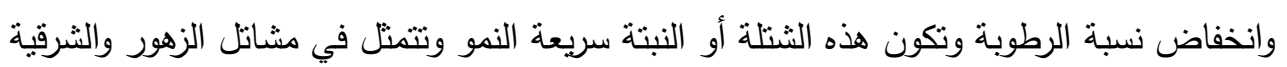
والأمير ومشروع غابات الكوت وكلية الزراعة وكاردينيا.

جدول(10) أهم الثتلات الصالحة للزراعة في مدينة الكوت

\begin{tabular}{|c|c|c|c|}
\hline النسبة \% & 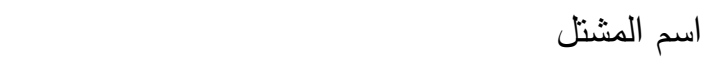 & 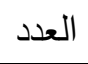 & 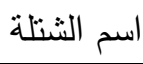 \\
\hline 77,77 & الواحة، الزهور، الثرقية، كاردينيا، زهور واسط، الأمير & 7 & 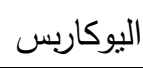 \\
\hline שז,r & مشروع غابات الكوت، كلية الزراعة، الثرقية & r & 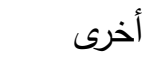 \\
\hline $1 \cdots$ & & 9 & المجموع \\
\hline
\end{tabular}

المصدر : من عمل الباحث بالاعتماد على الدراسة الميدانية.

\section{0 - كيفية زراعة نباتات الزينة}

تتباين زراعة نباتات الزينة في المشتل الواحد في مدينة الكوت لاختلاف نوع الثتلات المتواجدة

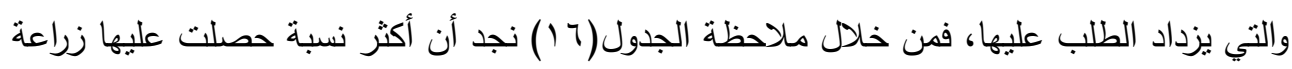

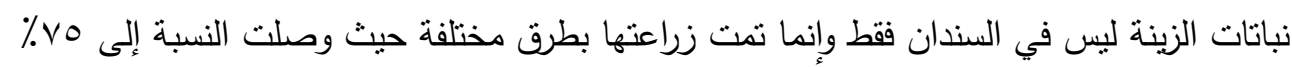
من الشاتل في مدينة الكوت و هץ ٪ يقومون بزراعة نباتات الزينة في السنادين. 
جدول(7 1 ) كيفية زراعة نباتات الزينة في مشاتل مدينة الكوت

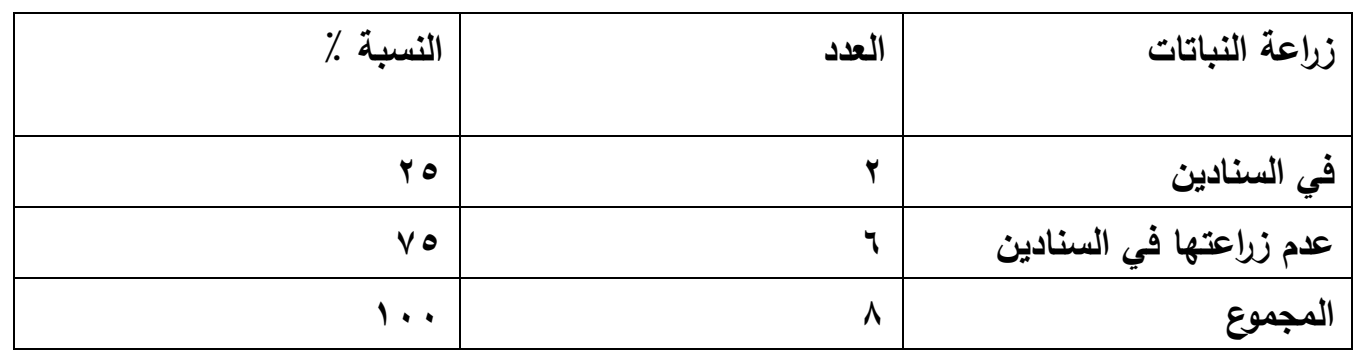

المصدر: من عمل الباحث بالاعتماد على الدراسة الميدانية.

$$
\text { 17 - إسيلة النقل }
$$

تمتل وسيلة النقل أهم العناصر التي يجب نوفرها لنقل الثتلات، اذ تمتل الأنواع المختلفة

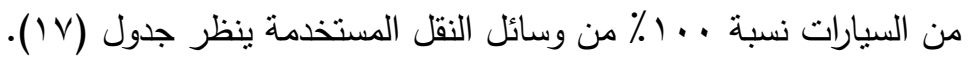

جدول(V ) ا نوع وسيلة النقل لمشاتل مدينة الكوت

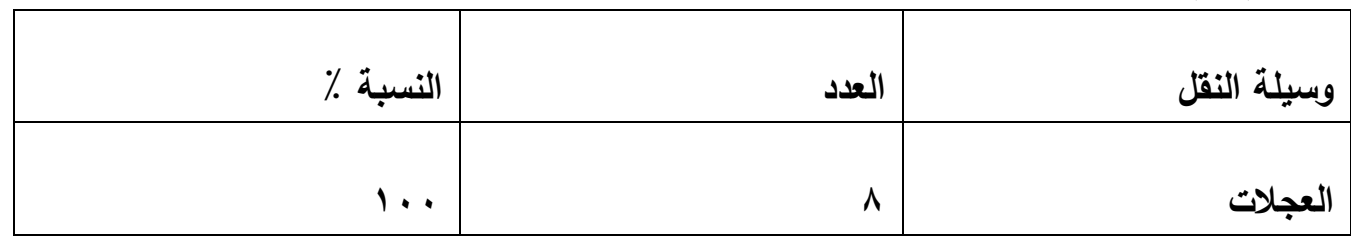

المصدر : من عمل الباحث بالاعتماد على الدراسة الميدانية.

\section{lV}

يعد التسويق من أبسط القضايا في العمل لكنه أكثر أهمية من حيث العرض والطلب ويعتمد إلى الى العي

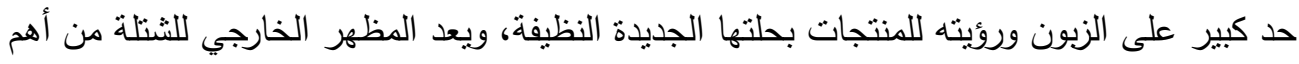

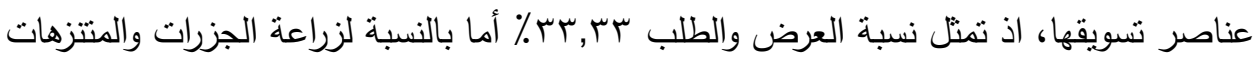

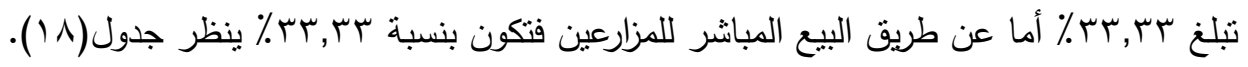




\begin{tabular}{|c|c|c|c|}
\hline & & \multicolumn{2}{|c|}{ جدول(1/) عملية التسويق في مشاتل مدينة الكوت } \\
\hline النسبة \% & 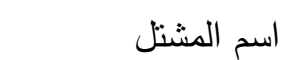 & 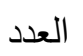 & عملية التسويق \\
\hline 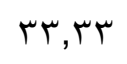 & كلية الزراعة & 1 & من خلال العرض والطلب \\
\hline سז, & 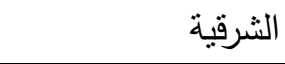 & 1 & الزراعة في الجزرات والمتنزهات \\
\hline שr, & مشروع غابات الكوت & 1 & بيع مباشر للمزارعين \\
\hline $1 \ldots$ & & $r$ & المجموع \\
\hline
\end{tabular}

المصدر : من عمل الباحث بالاعتماد على الدراسة الميدانية.

\section{1 ا-كميات الانتاج المسوقة}

تتباين كميات الإنتاج المسوقة تبعاً لعامل الطلب، فقد تباينت نسبة المشاتل المتواجدة في مدينة

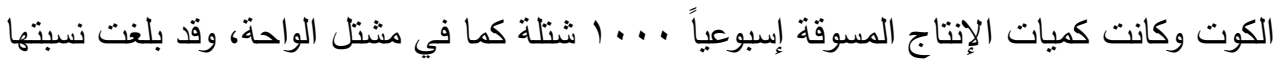

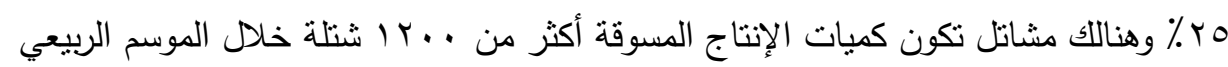

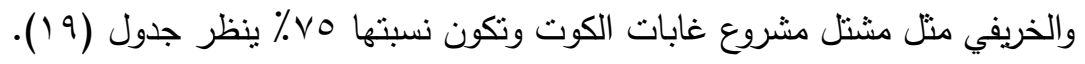

جدول(9 1 ) كميات الانتاج المسوقة من مشاتل مدينة الكوت

\begin{tabular}{|c|c|c|}
\hline النسبة \% & 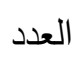 & كميات الانتاج (شتلة/ الاسبوع) \\
\hline ro & $r$ & $1 \ldots-\varepsilon \ldots$ \\
\hline vo & 7 & . . . 1 فأكثز \\
\hline $1 \ldots$ & $\wedge$ & المحموع \\
\hline
\end{tabular}

المصدر : من عمل الباحث بالاعتماد على الدراسة الميدانية. 
يظهر الجدول (·r) ان هناك تبايناً بين أنواع الثتلات المستوردة من مشتل لآخر ضمن مشاتل مدينة الكوت، فقد كانت نباتات الظل تمثل هب \% اذ أن هنالك مشاتل لا تستورد كمشتل الثرقية وكلية

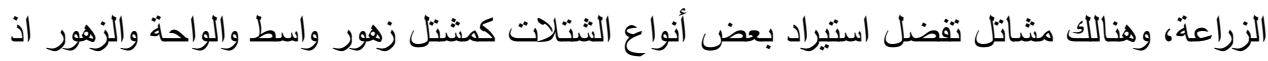

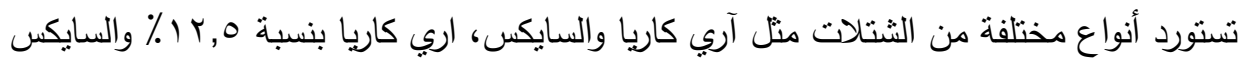
$\% 1 r, 0$

جدول(· · أنواع الثتلات المستوردة لمشاتل مدينة الكوت

\begin{tabular}{|c|c|c|c|}
\hline النسبة \% & اسم المشتل & العدد & أنواع الثتلات \\
\hline $1 Y, 0$ & الأمير & 1 & انتريوم \\
\hline ro & كاردينيا، الواحة & $r$ & نباتات الظل \\
\hline $1 Y, 0$ & زهور واسط & 1 & اري كايه \\
\hline $1 Y, 0$ & مشروع غابات الكوت & 1 & الزيتون \\
\hline$I_{1}, 0$ & الزهور & 1 & سايكس \\
\hline ro & كلية الزراعة، الثرقية & r & - \\
\hline $1 \ldots$ & & $\wedge$ & المجموع \\
\hline
\end{tabular}

المصدر : من عمل الباحث بالاعتماد على الدراسة الميدانية. 


\section{الاستنتاجات:}

1 • تقسم المشاتل من حيث الملكية إلى عدة أنواع منها (مشاتل عامة، مشاتل تجارية ومشاتل خاصة)

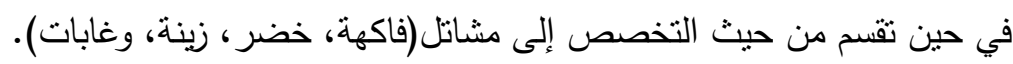

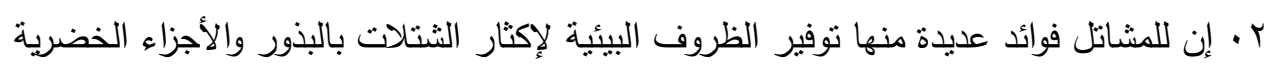
فضلاً عن تأثيراتها البيئية والنفسية للإنسان. r • هنالك عدة شروط يجب نوفرها في إنشاء المشتل كوجود المياه والتربة والمواصلات بين المشانياتل

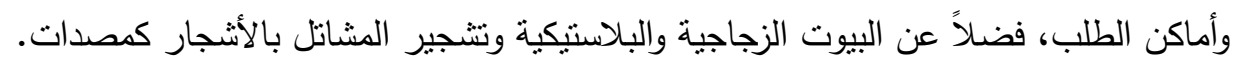

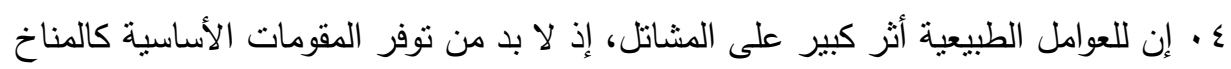

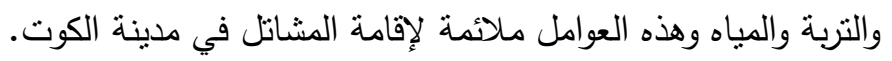

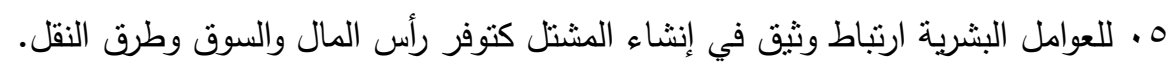

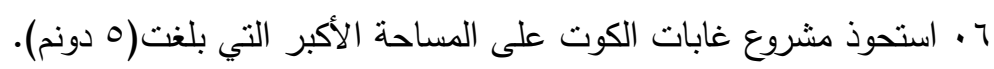

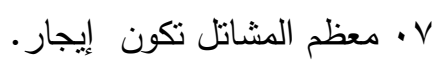
^ • تتتوع الثتلات بين نباتات الزينة والنباتات الظلية، إذ أن أكثر أنواع الثتلات الني يزداد الطلب

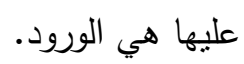


1 ا ـ ضرورة قيام المؤسسات الإدارية في مدينة الكوت وأهمها مديرية الزراعة بمسح شامل لصورة

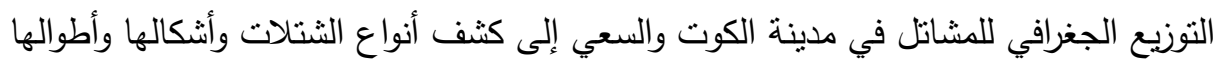
وألوانها وعن مستوى النمو ومعرفة الإمراض التي تصيب الثتلة أيضاً.

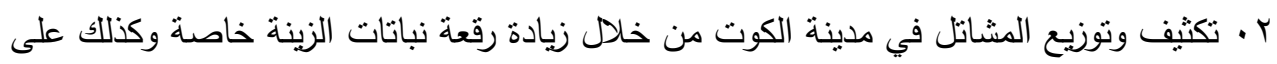
جانبي نهر دجلة حيث متنزهات المدينة. r • تكثيف الدراسات عن المشاتل في مدن عراقية أخرى لغرض المقارنة مع مدينة الكوت ومعرفة إذا ما كان عدد المشاتل في المدينة يفي بمسنوى الطموح. 


\section{المصادر:}

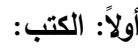

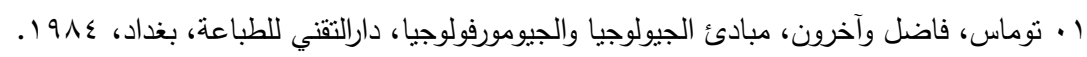

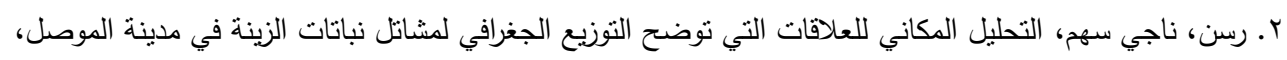

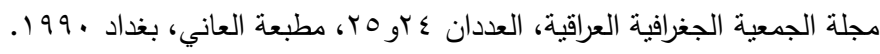

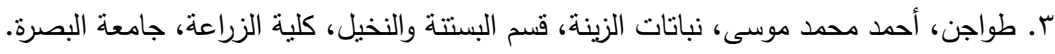
ع ـ العلاف، أياد هاني إسماعيل، المشتل، كلبة الزراعة والغابات، قسم البستتة وهندسة الحدائق، جامعة الموصل.

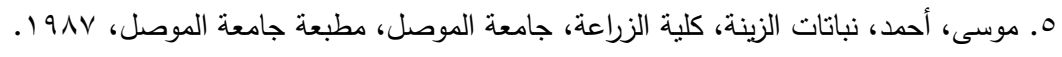
ثانيا: الاطاريح

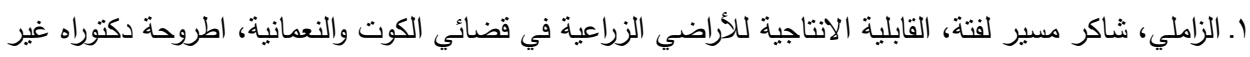

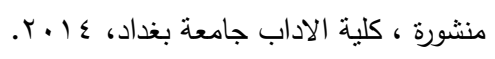
ثالثاً الانترنيت:

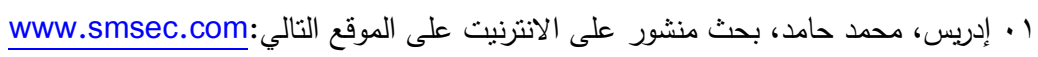

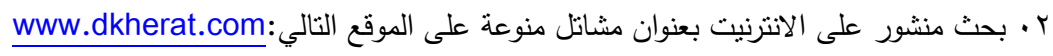

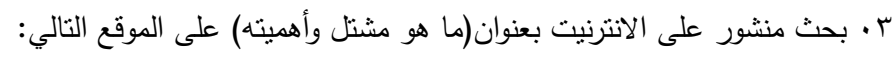
4377 /2462/content/minya.thebeehiv.org//http ـ • عمران، طلعت، كلية الزراعة، جامعة الإسكندرية، بحث منشور على الانترنيت على الموقع التالي: www.kenanaonline.net

ثالثاً: الدوائر الحكومية :- شعبة التحليل والرصد الإعلامي، المساحات الخضراء، با • ؟. 


\section{وزارة التعليم العالي والبحث العلمي}

\section{جامعة واسط/ كلية التربية/ قسم الجغرافية}

السادة الكرام..... يرجى تفضلكم بالإجابة على أسئلة استمارة الاسنبيان المبينة أدناه وتطلب ذلك بعض الكلمات والأرقام علماً بأن هذه المعلومات تستخدم لأغراض البحث العلمي فقط والخاصة بالبحث الموسوم(المشاتل في مدينة الكوت دراسة في جغرافية الزراعة) شاكرين تعاونكم معنا.... 1 إم المشتل

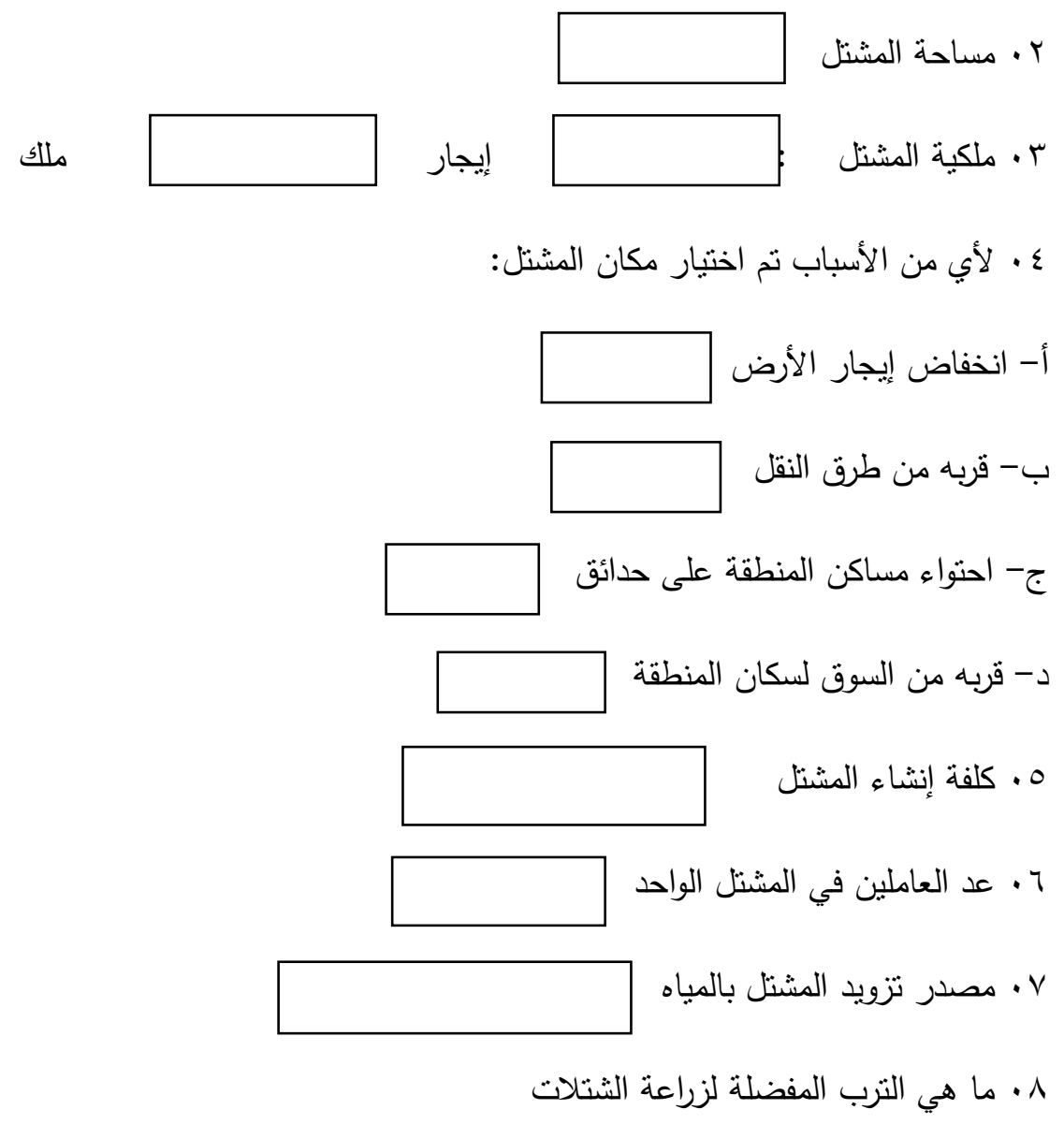


9 . أفضل طريقة لزراعة الشتلات

• 1 • أهم الأدوات التي تشتخدم في المشتل

11 + الأنواع التي توجد في المشنل

r ا • أكثر أنواع الشتلات التي يزداد الطلب عليها

با • أكثر الأمراض انتشاراً على الثتلات

ع 1 . أفضل أنواع الأسمدة المستخدمة في زراعتها

1 1 . أهم الشتلات الصالحة للزراعة في مدينة الكوت

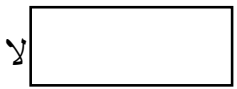

7 ا • ت تتم زراعة نباتات الزينة في السنادين فقط

IV

1 ا • كيف تتم عملية التسويق

9 1 ـكميات الإنتاج المسوقة

• r . أكثر أنواع الشتلات المستوردة 


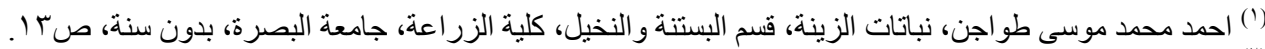

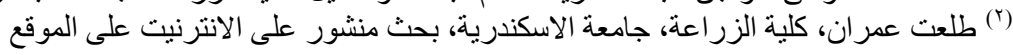
www.Kenananaonline

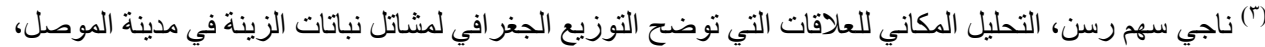

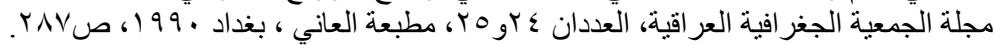

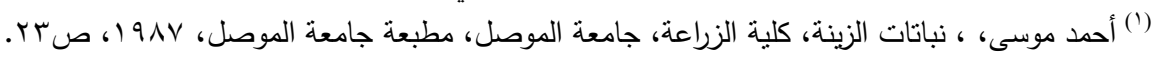

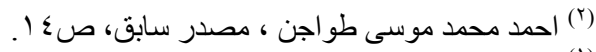

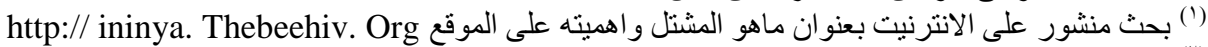

r)

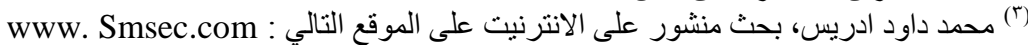

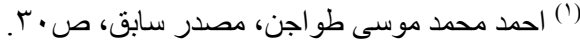

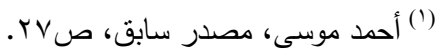

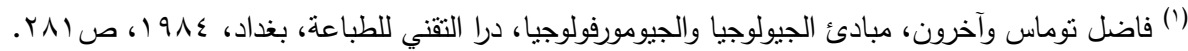

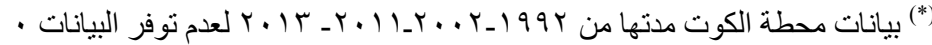

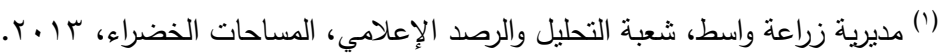

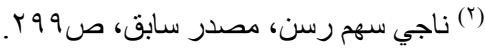

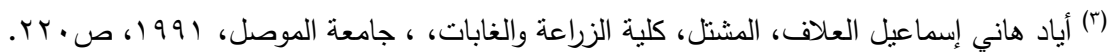

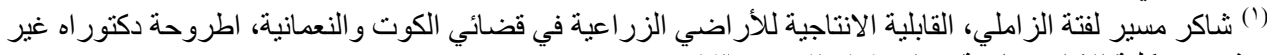

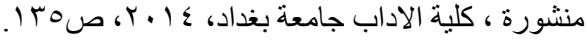

